\title{
CONTRIBUCIÓN DE LOS BOSQUES NATIVOS Y PLANTADOS A LA MITIGACIÓN DE LOS IMPACTOS DEL CAMBIO CLIMÁTICO EN CHILE EN UN CONTEXTO DE DESARROLLO SUSTENTABLE
}

\author{
Droppelmann, Fernando'; Grosse, Hans ${ }^{2}$ y Laroze, André ${ }^{3}$
}

\section{RESUMEN}

El sector forestal chileno es muy relevante para el país desde el punto de vista ambiental, económico y social. El país cuenta con 14,6 millones de hectáreas de bosques nativos y 2,3 millones de hectáreas de bosques plantados. Este sector puede constituir un aporte importante al logro de la meta de carbono neutralidad del país para el año 2050 por la vía de la captura de carbono y la reducción de emisiones. En este ámbito, se han generado distintas propuestas desde sectores de la academia, de los gremios profesionales, de la sociedad civil, de la industria y de los gremios forestales medianos y pequeños, entre otros.

El país requiere impulsar el desarrollo sustentable en el ámbito forestal. Desde esta posición, debe necesariamente plantearse ante las distintas propuestas con una mirada integradora de sus efectos en los ámbitos ambiental, económico y social, y debe considerar que, si bien el propósito de apoyar la mitigación del cambio climático es de primera importancia, también lo es impulsar el desarrollo sustentable del país, en particular de los segmentos más postergados. No basta con analizar las distintas opciones desde una mirada puramente física, es completamente relevante considerar los costos de las distintas propuestas para analizarlas, pues reflejan el nivel de sacrificio de otros bienes o los recursos que el país requerirá para implementarlas, así como la posibilidad de atraer recursos privados para su financiamiento.

Al igual que el tema de costo eficiencia, es muy importante considerar tanto los aspectos de eco eficiencia en las distintas propuestas como la realidad de los distintos territorios en cuanto a la factibilidad e impacto en ellos de las distintas soluciones, sin olvidar la realidad de que la mayoría de las áreas objeto de intervenciones serán privadas, con actores que requieren un retorno económico en plazos razonables y actividades industriales que también dependen de ello.

Al ponderar opciones de forestación, no es correcto comparar plantaciones exóticas con bosque nativo en su capacidad de captura de carbono, asumiendo que las primeras serán cortadas para producción maderera y los segundos no. Lo que se está haciendo en este caso es comparar entre dos regímenes distintos; producción maderera versus régimen de sumidero permanente. Las comparaciones deben realizarse para ambos casos en régimen similar; exóticas versus nativas en régimen de producción y similar comparación para ambas como sumidero permanente. Bajo los supuestos de análisis en este estudio y comparando regímenes similares, el carbono capturado por forestaciones de rápido crecimiento tiene un costo social significativamente menor que las forestaciones con especies nativas, tanto en régimen de producción como en régimen de sumidero permanente.

Reconociendo que existen preferencias en sectores de la sociedad por algunos tipos de especies en relación a otras, concretamente nativas respecto a exóticas, no existen elementos basados en la ciencia que permitan descartar el uso de especies introducidas si se toman las precauciones de una silvicultura adecuada. Al incorporar una mirada integral se hace notoria la necesidad de apreciar la complementariedad que puede existir entre distintas soluciones. El intento

\footnotetext{
${ }^{1}$ Dr. Ingeniero Forestal. Instituto de Silvicultura Universidad Austral de Chile. Director Ejecutivo Cooperativa de Mejoramiento Genético Forestal. fdroppel@uach.cl

${ }^{2}$ Dr. Ingeniero Forestal. Subdirector Ejecutivo. Instituto Forestal hgrosse@infor.cl

${ }^{3}$ Dr. Ingeniero Forestal. Secretario Ejecutivo. Sistema Chileno de Certificación de Manejo Forestal Sustentable CERTFOR, Chile
} 
de abordar la problemática desde visiones o recetas únicas, no resulta funcional y podría conducir a propuestas poco realistas o impracticables.

Debido al gran impacto de sustitución de materiales constructivos emisores y secuestro de carbono por parte de la construcción en madera, las políticas forestales debieran no solo preocuparse de la captura de carbono, sino también de la producción eco eficiente de madera, para sustentar una creciente participación de este material en la construcción. Por lo anterior, es recomendable combinar soluciones forestales tipo sumidero permanente con soluciones mixtas que consideren producción sostenible.

Palabras clave: Bosques Nativos, Bosques Plantados, Captura de Carbono, Reducción de Emisiones 


\section{SUMMARY}

The Chilean forestry sector is very relevant for the country from an environmental, economic and social point of view. The country has 14.6 million hectares of native forests and 2.3 million hectares of planted forests. This sector can provide an important contribution to the achievement of the carbon neutrality goal of the country by 2050, through carbon sequestration and emission reduction. In this area, different proposals have been generated from sectors of the academy, professional associations, civil society, industry and medium and small forest guilds, among others.

The country needs to boost sustainable development in the forestry field. From this position, must necessarily be considered the different proposals with an integrative view of their effects in the environmental, economic and social spheres. Although the purpose of supporting climate change mitigation is of first importance, it is also important to promote the sustainable development of the country, in particular of the less favoured segments. It is not enough to analyze the different options from a purely physical perspective, it is completely relevant to consider the costs of the different proposals to analyze them, since they reflect the level of sacrifice of other goods or the resources that the country will require to implement them, as well as the possibility of attract private resources for financing.

As well as the issue of cost efficiency, it is very important to consider both, the aspects of eco-efficiency in the different proposals and the reality of the different territories in terms of the feasibility and impact on them of the different solutions. Also must no be ignored the reality that most of the areas subject to interventions will be private, with actors that require a reasonable economic return and industrial activities that also depend on it.

When weighting afforestation options, it is not correct to compare exotic plantations with native forest in their carbon capture capacity, assuming that the former will be cut for timber production and the latter will not. What is being done in this case is to compare between two different regimes; timber production versus permanent sink regime. Comparisons should be made for both cases under a similar regime; exotic versus native in production regime and similar comparison for both as permanent sink. Under the assumptions of analysis in this study and comparing similar regimes, carbon captured by fast-growing afforestation has a significantly lower social cost than afforestation with native species, both in the production regime and in the permanent sink system.

Recognizing that there are preferences in sectors of society for some types of species in relation to others, specifically native to exotic species, there are no science-based elements that allow the use of introduced species to be ruled out if precautions are taken to perform adequate forestry. From an integral point of view, the need to appreciate the complementarity that may exist among different solutions becomes evident. The attempt to address the problem from unique visions or recipes is not functional and could lead to unrealistic or impracticable proposals.

Due to the great impact of substitution of emitting building materials and the carbon sequestration by wood construction, forestry policies should not only be concerned with carbon sequestration, but also with the eco-efficient production of wood, to support a growing participation of this material in construction. Therefore, it is advisable to combine permanent sink forest solutions with mixed solutions that consider sustainable production.

Keywords: Native Forests, Planted Forests, Carbon Capture, Emission Reduction 


\section{CAPTURA DE CARBONO EN UN MARCO DE SUSTENTABILIDAD}

El sector forestal chileno es muy relevante para el país desde el punto de vista ambiental, económico y social. El país cuenta con 14,6 millones de hectáreas de bosques nativos y 2,3 millones de hectáreas de bosques plantados (INFOR, 2019), con un sector industrial muy diverso, desde grandes compañías integradas hasta más de 1000 pequeñas y medianas industrias madereras, cerca de 250 viveros, numerosas empresas de servicios, 22 mil propietarios de plantaciones forestales y cerca de 80 mil propietarios de bosques nativos. Entre empleo directo, indirecto y no asalariado más de 400 mil personas reciben ingresos del sector, cuyo efecto multiplicador en la economía se cuenta entre los diez más altos.

Ante la inminencia de la COP 25 , se ha dinamizado el debate ambiental centrado en el rol de los bosques, principalmente enfocado en su capacidad de captura de carbono, al evidenciarse que el año 2016 contribuyó con la captura de $62 \%$ de las emisiones de $\mathrm{CO}_{2}$ del país; y también ante la meta trazada por el Gobierno de lograr una economía carbono neutral al año 2050. En el ámbito de este debate se han generado distintas propuestas desde sectores de la academia, de los gremios profesionales, de la sociedad civil, de la industria y de los gremios forestales medianos y pequeños, entre otros.

El país requiere impulsar el desarrollo sustentable en el ámbito forestal. Desde esta posición, debe necesariamente plantearse ante las distintas propuestas con una mirada integradora de sus efectos en los ámbitos ambiental, económico y social, y debe considerar que, si bien el propósito de apoyar la mitigación del cambio climático es de primera importancia, también lo es impulsar el desarrollo sustentable del país, en particular de los segmentos más postergados.

De este modo, se debe plantear que habrá proyectos cuyo principal foco podrá ser la mitigación del cambio climático, con eventuales externalidades positivas (o sin ellas) en los ámbitos económico y social, pero habrá otros proyectos cuya prioridad principal será dinamizar aspectos de estos últimos ámbitos, idealmente contribuyendo positivamente en forma complementaria a la captura de $\mathrm{CO}_{2}$.

Forestar, reforestar, regenerar bosques naturales y restaurar territorios y ecosistemas emergen como temas relevantes. Estos desafíos requieren grandes aportes desde el punto de vista del conocimiento, pero, además, inversiones muy significativas, pues de no disponerse recursos los mejores planes quedarán solo en el ámbito de la retórica. Es completamente relevante considerar los costos de las distintas propuestas para analizarlas, pues reflejan el nivel de sacrificio de otros bienes o los recursos que el país requerirá para implementarlas. Los recursos fiscales, siempre escasos, compiten con necesidades acuciantes como las pensiones, la educación y la salud; de modo que, para lograr los impactos requeridos, es fundamental atraer la inversión privada, por una parte; y por otra, asegurarse de lograr las combinaciones más costo eficientes en términos de pesos por tonelada de $\mathrm{CO}_{2}$ capturada o por empleo generado.

Al igual que el tema de costo eficiencia es muy importante considerar los aspectos de eco eficiencia en las distintas propuestas; optimizar el uso del suelo, del agua y minimizar externalidades negativas por unidad de carbono capturada o empleo generado. Se debe incorporar también la realidad de los territorios, donde una diversidad de usos del suelo debe convivir para que el paisaje sea más funcional y resiliente, y así mejore el bienestar humano. En efecto, como cada territorio tiene su historia particular, es necesario considerar las necesidades de la gente en cada uno, sin olvidar que probablemente la mayoría de las áreas objeto de intervenciones serán privadas, con actores que requieren un retorno económico en plazos razonables y actividades industriales que también dependen de ello.

De esta forma, al incorporar una mirada integral se hace notoria la necesidad de apreciar la complementariedad que puede existir entre distintas soluciones. Las reflexiones anteriores muestran que la discusión de blanco o negro sobre el tema de cómo forestar, reforestar o restaurar, buscando hacer prevalecer visiones o recetas únicas, no resulta útil y eventualmente podría 
conducir a soluciones poco realistas o impracticables.

En este contexto, tanto bosques nativos como bosques plantados tienen un rol relevante que cumplir. Los bosques nativos, al estar en crecimiento, aportan en forma muy significativa con las capturas de carbono. Si bien incrementan su biomasa a tasas inferiores a las plantaciones forestales de rápido crecimiento, existe una mucho mayor superficie de bosque nativo que permite contribuir con la captura total a nivel país y, además, este recurso no se hace principalmente cargo de la producción maderera, por lo que en muchos casos puede estar en crecimiento largo tiempo hasta poder entregar esta opción productiva, proporcionando valiosos servicios ecosistémicos. En el futuro se espera que estos bosques también contribuyan en mayor medida a las economías locales con producción maderera sustentable y productos forestales cumpliendo con su función multipropósito.

Las plantaciones forestales, por su parte, cumplen hoy el importante rol de abastecer la industria forestal, donde hay un gran número de pymes madereras que requieren suministro para sobrevivir y crecer. Esta cadena de valor da empleo y moviliza el desarrollo de varias regiones del país. Si bien hoy este recurso se encuentra en equilibrio entre cosecha y reforestación, en la medida que el stock de plantaciones se incremente, dicho incremento capturará carbono a altas tasas, contribuyendo también a la búsqueda de un futuro carbono neutral. No debe perderse de vista el rol que estas formaciones cumplen absorbiendo los requerimientos productivos, ya que de no existir deberían ser suministrados por los bosques nativos, generando las emisiones asociadas en dichos bosques.

Si se busca otorgar a la propuesta de Política Forestal 2015 - 2035 una proyección de política de Estado que trascienda a un Gobierno determinado, se debe considerar el espíritu de dicha propuesta. En este sentido, y con una mirada de sustentabilidad que abarque los ejes social, ambiental y económico, deben manejarse los bosques nativos para potenciar su producción de madera y de servicios ecosistémicos, fortaleciendo con ello su conservación, a la vez que forestar con plantaciones terrenos descubiertos sin alternativa agrícola, apuntando a una participación cada vez más inclusiva de todos los actores del sector forestal y con especial foco en la pyme maderera $y$ forestal.

\section{BOSQUES NATIVOS Y BOSQUES PLANTADOS}

\subsection{Complementariedad Ante Demandas de Madera en el Mundo y en Chile}

El connotado científico neozelandés Wink Sutton escribía en su artículo Plantation Forests Protect our Biodiversity (1995) sobre los roles que tiene para el hombre la biodiversidad y la especialización. El ser humano necesita disponer de una amplia variedad de opciones para obtener alimentación, energía, materiales de construcción, fibras, medicinas y otros, gran parte de las cuales las provee la biodiversidad, la cual, además, es fundamental para mantener el equilibrio natural y, por ende, la vida en el planeta. De entre muchas opciones, el hombre elige solo las especies más eficientes para los distintos usos y las reproduce. Sutton indica que cerca de un $70 \%$ de las necesidades de alimento es abastecido solo por 9 especies de vegetales, 1 de aves y 3 de otros animales.

La única forma en que el mundo pueda alimentar su población actual (más de 7 mil 500 millones de habitantes) es mediante las técnicas agrícolas y ganaderas especializadas, muchas de las cuales se usan desde hace más de 8 mil años. En la época de la caza y la recolección, se requerían 100 hectáreas de bosque biodiverso por persona para alimentarse. Con ese estándar, hoy se necesitaría 180 veces todos los bosques del planeta para sobrevivir.

Este aumento enorme de la ecoeficiencia (menor uso de recursos naturales para un cierto fin), que ha hecho posible la supervivencia del ser humano y a la vez conservar gran parte del planeta, se evidencia en índices tales como que desde 1960 a la fecha, la tierra requerida para 
alimentar a una persona bajó a la mitad, y en los últimos 20 años el requerimiento de tierra para la agricultura bajó en 50 millones de hectáreas (Asafu-Adjaye et al., 2015).

Con los bosques pasa algo similar; el mundo utiliza unos 3.800 millones de metros cúbicos de madera al año, la mitad para combustible, y se espera (WWF, 2012) que esta demanda supere los 7.000 millones de metros cúbicos al 2030. Esto podría someter a una enorme presión a los 4 mil millones de hectáreas de bosques (principalmente nativos) del planeta, presión potencialmente muy destructiva para estos, dado que es imposible garantizar su adecuado manejo ante una demanda de esa magnitud.

Las plantaciones forestales hoy absorben casi un $40 \%$ de la demanda mundial y pueden absorber la demanda adicional utilizando del orden de un décimo de superficie respecto a otros bosques promedio del mundo, lo que significa solo un $5 \%$ respecto a la superficie actual. Son una respuesta especializada, a partir de una selección de las especies más eficientes para producir madera que permita regular la presión de demanda y hacer posible la conservación de los ecosistemas naturales, al igual que lo hizo la agricultura.

Así, los bosques naturales, ricos en biodiversidad, y las plantaciones, eficientes en producir madera, son recursos complementarios y no antagónicos. Sin los primeros no se podría seleccionar las más eficientes especies madereras y sin plantaciones no se podría asegurar la conservación de los bosques naturales del país y del mundo. El foco de preocupación debiera ser que las plantaciones se ejecuten en forma sustentable. El concepto de complementariedad por absorción de demanda de madera queda claramente explicado en el documento Living Forests Report: Chapter 4 (WWF, 2012), así como en artículo de Fenning and Gershenzon (2002).

La situación marco que se está dando en Chile y en el mundo apunta cada vez más al uso de recursos sustentablemente, incluyendo a la madera y sus derivados como una opción doblemente atractiva, ya que los bosques fijan carbono de la atmósfera y lo mantienen fijo en los productos que de ellos se obtienen. Según las proyecciones de FAO (2019) los factores que más afectarán la demanda de productos forestales son:

Los cambios demográficos en el mundo, donde la población mundial en el año 2005 fue de 6,5 billones y la proyección para el 2020 es de 7,5 llegando a 8,2 en 2030, lo que significa un incremento de un $26,1 \%$.

- Crecimiento económico continuo, desde US\$16 trillones en el año 1970 a US\$ 47 trillones en 2005 y proyectado para 2030 en US\$100 trillones.

- Cambios en la producción regional. Entre los años 1970 y 2005 las economías más desarrolladas aportaron la mayor parte del producto interno bruto del mundo. Esto va a cambiar significativamente por el crecimiento de los países en desarrollo, especialmente del Asia.

- Nuevas políticas y regulaciones ambientales harán que más bosques serán excluidos de la producción maderera.

- $\quad$ Políticas de energía fomentarán el uso de biomasa, incluyendo la madera.

Otros factores que incidirán en la producción maderera son la baja de cosechas en bosques naturales y la aparición de plantaciones forestales como el mayor recurso para abastecer la demanda de madera. También incidirán los desarrollos tecnológicos, el incremento de la productividad de las plantaciones forestales mediante el mejoramiento genético, la reducción de demanda con la ayuda del reciclaje, la mayor recuperación, el mayor uso de productos compuestos y la producción de combustibles biológicos.

Frente a un escenario de demanda creciente de productos forestales en el mundo Chile 
tiene la opción de tomar o dejar la oportunidad de ser parte de la oferta sobre la base de bosques manejados sustentablemente. Debe tenerse presente que en el año 1950 el volumen de madera que requería el mundo era provisto prácticamente en su totalidad por los bosques nativos, pero esto cambia drásticamente por cuanto se estima que al año 2050 entre el 75 y el $80 \%$ de la demanda industrial de madera provendrá de plantaciones (Sohngen et al.,1999).

Se ofrecen dos macro opciones para cumplir con este fin y consisten en aumentar la superficie de árboles plantados en terrenos desprovistos de estos y en realizar silvicultura en los bosques nativos más atractivos para lograr madera de alta calidad junto a la biodiversidad ecosistémica y la protección de los suelos.

\subsection{Bosques Plantados}

\subsubsection{Aumento de la Superficie de Bosques Plantados}

Chile sufrió deforestación masiva durante la época de la colonia, con gran intensidad durante el siglo 19 y hasta la primera mitad del siglo 20. En la zona norte era la necesidad de biomasa para la minería que llevó en la región de Coquimbo hasta el descepado de los árboles y en la zona sur a roces a fuego intensos para habilitar terrenos para la ganadería y agricultura. Detallados relatos sobre lo sucedido y la dramática pérdida de suelos por erosión se encuentran en la literatura (Ovalle, 1646; Rosales, 1674; Molina, 1810; Gay, 1838; Olivares, 1864; Pérez Rosales, 1886; González de Nájera, 1889; Martin, 1923; Elizalde, 1958; Trivelli, 1970; Hartwig, 1986; Otero, 2006; Grosse, 2009).

Pese a que Chile forestó cerca de 180 mil hectáreas hasta el año 1950 (Cerda et al., 1992) y llegó a completar cerca de 2,5 millones de hectáreas en el año 2016 (INFOR, 2019), existe una superficie de cerca de 2,6 millones de hectáreas que continúa bajo procesos de erosión y que sería forestable (Beltrán, 2013). La mayor superficie forestable se encuentra en la región de Aysén con un $26 \%$, seguida por La Araucanía con un 20,9\% y Bio Bio con un 15,6\% (Cuadro № 1).

\section{SUPERFICIE POTENCIALMENTE FORESTABLE}

\begin{tabular}{|l|r|r|}
\hline \multirow{2}{*}{ Región } & \multicolumn{2}{|c|}{ Superficie Potencialmente Forestable } \\
\cline { 2 - 3 } & (ha) & \multicolumn{1}{|c|}{ (\%) } \\
\hline O'Higgins & 288.261 & 11,0 \\
Maule & 294.152 & 11,2 \\
Bio Bio & 410.536 & 15,6 \\
La Araucanía & 550.271 & 20,9 \\
Los Ríos & 65.693 & 2,5 \\
Los Lagos & 338.342 & 12,9 \\
Aysén & 683.055 & 26,0 \\
\hline Total & $\mathbf{2 . 6 3 0 . 3 1 0}$ & $\mathbf{1 0 0 , 0}$ \\
\hline
\end{tabular}

(Fuente: Beltran, 2013)

De esta superficie, se estima que al menos 500 mil hectáreas se podrían forestar con el doble propósito de detener la erosión y a su vez generar volumen productivo según lo propuesto por el Consejo de Política Forestal ${ }^{4}$. Los terrenos se encuentran en manos de pequeños y medianos propietarios, para los cuales la forestación sería una alternativa interesante para su

\footnotetext{
${ }^{4}$ http://www.conaf.cl/nuestros-bosques/bosques-en-chile/consejo-de-politica-forestal/
} 
desarrollo al igual que para la pyme maderera con más de 1.000 instalaciones $^{5}$. Las alternativas para los propietarios varían desde bosques con un énfasis en producción de madera de alta calidad, con clara opción de uso para la construcción en madera, hasta la opción de cubierta permanente, considerando siempre la producción en paralelo de productos forestales no madereros y la protección del suelo. Para todas las opciones es preciso contar con incentivos estatales que permitan el establecimiento, el manejo y la mantención de las plantaciones. La especie a elegir dependerá del sitio en particular, es decir, del conjunto de factores edáficos, climáticos y bióticos, siendo en la mayoría de los casos las precipitaciones medias anuales el aspecto más condicionante para el éxito.

Si se pretende obtener crecimientos acelerados habrá que optar en suelos empobrecidos y dependiendo de la zona geográfica por especies pioneras, capaces de instalarse en lugares abiertos sin protección alguna. Entre estas se encuentran principalmente pino radiata (Pinus radiata), eucaliptos (Eucalyptus globulus, Eucalyptus nitens y otros), pino oregón (Pseudotsuga menziesii), pino ponderosa (Pinus ponderosa), álamos (Populus spp) y acacias (Acacia spp) (Prado et al., 1986; Prado y Barros, 1989).

En suelos con poco o sin deterioro, como praderas en desuso desde el sur de la región del Bio Bio a Los Lagos, con períodos estivales con sequías de corta duración, se podría plantar también raulí (Nothofagus alpina), roble (Nothofagus obliqua) e híbridos roble $\mathrm{x}$ raulí, entre otras especies. Para tener éxito con las especies nativas nombradas se debe optar por técnicas de plantación intensivas para luego continuar con silvicultura temprana (Tuley, 1989; Grosse et al.,1991; Grosse et al., 1993; Grosse y Pincheira, 1998; Grosse, 2009; Ríos, 2008; Mujica, 1997). Todas las especies mencionadas, en plantaciones bajo silvicultura intensiva, culminan su crecimiento anual corriente cerca o antes de los 10 a12 años, por lo cual se las puede calificar de rotación corta ( 25 a 35 años).

Además de los aspectos técnicos que se deben tener en cuenta para elegir una determinada especie, es muy importante considerar los aspectos económicos asociados a la logística de preparación del terreno para plantar, la disponibilidad de material genético adaptado a dichas condiciones, la existencia de caminos (accesibilidad) y las distancias a centros de consumo (industrias existentes y potenciales que se puedan desarrollar en el futuro). Se debe tener en cuenta también que las principales especies introducidas, como pino radiata y eucaliptos, han sido sometidas a procesos de mejoramiento genético que las hacen ser muy atractivas en los procesos industriales (rendimientos mayores en fábrica), aspecto que impacta en el precio final de los productos derivados del bosque.

\section{Pinus radiata}

Especie ampliamente plantada en Chile, Nueva Zelanda, Australia y en el norte de España. Como parte de sus principales características destaca su rápido crecimiento, buena forma, adaptabilidad a una amplia variedad de sitios, propiedades de la madera que le han permitido posicionarse en los mercados mundiales en una diversidad de productos. En Chile se la planta desde la zona de Valparaíso hasta la zona de Puerto Montt. Se la ha empleado como la especie para neutralizar el avance de las dunas, detener procesos erosivos, reincorporar a la producción terrenos completamente degradados por la agricultura y también aquellos con tantas limitantes para el crecimiento como lo son los arenales de la región del Bio Bio. Es una especie fácil de producir en vivero, se ha logrado un desarrollo genético que permite disponer de las mejores combinaciones genéticas para las distintas condiciones de sitio y hay esquemas de manejo silvícola conocidos para las distintas opciones de producción en rotaciones de 20 a 24 años.

\footnotetext{
5 https://wef.infor.cl/
} 


\section{Eucalyptus globulus}

Esta especie fue la segunda especie más plantada en Chile hasta hace una década, ello especialmente por las extraordinarias propiedades de su madera y por su capacidad de rebrotación luego de la cosecha. Su madera es por lejos la preferida para producción de celulosa de fibra corta, razón por la cual desde Chile se inició la exportación de astillas de esta especie a los mercados asiáticos hace ya casi 30 años.

Prospera en una amplia variedad de sitios desde la región de Valparaíso a la región de Los Lagos, con los mejores resultados en las zonas más costeras. Su poca tolerancia a las heladas es su principal limitante y en la última década también ha sufrido problemas por algunos insectos y hongos, todo lo cual ha llevado a disminuir su participación en los programas de forestación.

Se dispone de amplios conocimientos para su establecimiento, con material genético desarrollado para condiciones de sitio específicas en que sigue siendo una especie interesante (evitando secano central), con rotaciones de 11 a 13 años.

\section{Eucalyptus nitens}

Eucalyptus nitens es actualmente la segunda especie más plantada, superando a Eucalyptus globulus. Se caracteriza por su rápido crecimiento, buena forma, tolerancia al frío y buena sanidad, destacando con extraordinarios desempeños en la precordillera de Los Andes y zonas con menores temperaturas, pero con buenos regímenes pluviométricos, por ello se la planta masivamente desde la región del Bio Bio hasta la provincia de Llanquihue.

Sus principales limitantes radican en las propiedades de su madera, que presenta tensiones de crecimiento, que dificultan su uso en productos de madera sólida, y su menor densidad y rendimiento pulpable. Se ha intentado compensar esto aumentando su período de rotación a $15-16$ años.

\section{Eucalyptus globulus $x$ Eucalyptus nitens}

Híbrido resultante del cruzamiento entre estas dos especies. Durante los últimos 17 años se ha realizado una muy importante inversión en investigación y desarrollo para lograr generar estos híbridos. Se logra reunir las mejores características de $E$. nitens, en materia de crecimiento y tolerancia a frío, y las mejores propiedades de madera de $E$. globulus, en cuanto a densidad y rendimiento pulpable.

Estos híbridos mejoran la rentabilidad de la inversión forestal en forma muy significativa, dependiendo del tipo de suelo, las condiciones de clima y la distancia a las industrias. La rentabilidad puede estar un $50 \%$ sobre la de E. nitens.

Recientemente, en el marco de la Cooperativa de Mejoramiento Genético Forestal, se ha realizado un convenio entre la empresa privada que dispone de este material, la Cooperativa y 6 viveros forestales, para poner a disposición de cualquier forestador chileno este valioso material.

Desde un punto de vista de captura de carbono resulta muy atractiva esta alternativa, por cuanto capta el volumen de $E$. nitens, pero una mayor cantidad de madera en dicho volumen por cuanto tiene la densidad de E. globulus. 


\section{Nothofagus alpina y Nothofagus obliqua x Nothofagus alpina (RoRa)}

Raulí, roble e híbridos de roble y raulí. Durante los últimos 30 años mucho se ha planteado la necesidad de diversificación de la producción forestal, pero pocas alternativas reales existen con especies nativas. Resultados de investigación de los últimos 15 años (Donoso et al., 1990) muestran a raulí como una especie de real potencial. Ello también se refuerza con las únicas plantaciones de raulí realizadas con silvicultura intensiva en la zona de Panguipulli, que actualmente tienen 17 años, con árboles de 25 a $32 \mathrm{~cm}$ de diámetro que demuestran el potencial existente.

Un problema de la especie es su escasa e irregular producción de semillas, que dificulta una producción sostenida de plantas y a costos razonables. Sin embargo, en un reciente proyecto, iniciado el año 2011 en la Universidad Austral de Chile, se pudo desarrollar un sistema de reproducción vegetativa que permite que el costo de las plantas pueda ser similar al de las especies introducidas (pino radiata o eucaliptos).

Está debidamente documentado que los híbridos son una excelente alternativa como método de mejoramiento genético por cuanto permiten lograr genotipos que combinan las mejores características de las especies progenitoras (hibridación combinatoria). Expertos manifiestan que los híbridos naturales entre las especies del genero Nothofagus son bastante comunes, siendo muy interesantes los híbridos entre roble y raulí, tanto desde el punto de vista productivo como adaptativo (crecimiento y calidad de madera de raulí, crecimiento y adaptabilidad a diversos sitios de roble), como también desde el punto de vista de aporte a la variabilidad.

El proceso de hibridación natural puede producir combinaciones genéticas que superen la baja diversidad genética de las poblaciones expuestas a condiciones de estrés o que se encuentran sujetas a un rápido cambio de las condiciones climáticas. Por lo tanto, la hibridación debiera ser, en general, considerada como un importante proceso evolutivo y las poblaciones híbridas no debieran ser ignoradas como fuente potencial para la restauración de los bosques (Frascaria-Lacoste et al., 2011).

Las posibilidades de lograr híbridos que, manteniendo las características madereras de $N$. alpina, sean capaces de desarrollarse en una mayor variedad de ambientes son promisorias (Donoso et al., 1990). Teniendo en cuenta estos antecedentes y otros, desde hace tres años en la Universidad Austral de Chile se está trabajando en dos proyectos para desarrollar híbridos RoRa, ello tanto utilizando colectas de híbridos naturales como también realizando cruzamientos controlados entre ambas especies.

Lo señalado, tanto de raulí como especie pura y del híbrido RoRa, podrá ser de uso masivo real en la medida que existan los recursos requeridos para la investigación y el desarrollo necesario para generar plantas de buena calidad genética, con varias poblaciones que permitan cubrir distintas zonas geográficas y para evaluar las distintas opciones de manejo y utilización industrial.

Paralelamente, es fundamental disponer de los incentivos correspondientes para que los propietarios tomen la decisión de forestar con estas alternativas nativas, como la única forma de escalar los niveles de forestación que permitan en el futuro generar una industria asociada a estas especies.

Es clave que la silvicultura que se aplique a estas plantaciones nativas sea intensiva, procurando obtener los mismos atributos de rendimiento y uniformidad que se buscan con las especies introducidas, de lo contrario no serán una realidad en el mercado de la madera en el futuro. 
En síntesis, existen oportunidades reales probadas y validadas con las principales especies introducidas (Pinus radiata, Eucalyptus globulus, Eucalyptus nitens, Eucalyptus globulus $x$ Eucalyptus nitens), más dos opciones de especies nativas con potencial real (roble, raulí e híbrido roble $x$ raulí), que deben ser usadas teniendo en cuenta criterios eminentemente técnicos que darán sustentabilidad a las inversiones asociadas al uso de cualquiera de esas opciones. Al mismo tiempo debe generarse un decidido programa de recuperación y manejo del bosque nativo que tenga vocación productiva.

\subsubsection{Bosques Plantados, Sustentabilidad y Cambio Climático}

Los bosques plantados, o plantaciones forestales, establecidos y manejados sustentablemente, pueden cumplir un importante rol en la mitigación del cambio climático, ya sea complementando un rol principal de producción maderera o siendo utilizados con fines principalmente ambientales, entre estos como sumideros permanentes de carbono.

Es importante notar que cuando se pretende formar bosques nativos, en buena parte de los casos el proceso parte por una plantación con especies nativas o generándolos mediante la promoción de la regeneración, natural o asistida, la cual, en su primera fase, que puede tomar muchos años, se comporta como cualquier bosque plantado.

Debido a que la captura de carbono está directamente relacionada con la fotosíntesis y por lo tanto con la capacidad de generación de biomasa, las plantaciones de especies de rápido crecimiento (en la mayoría de los casos exóticas) presentarán mayores capturas anuales que los bosques nativos (Cuadro $\mathrm{N}^{\circ} 5$ ). Si se las dejara crecer como sumideros permanentes, al llegar al equilibrio finalmente alcanzarían un stock capturado similar a los bosques nativos en un sitio también similar, pero llegarían a este equilibrio en un plazo considerablemente más corto.

En su etapa de senectud y desmoronamiento, estos bosques plantados con fines de conservación, pueden dar paso de manera natural a un bosque de especies nativas a partir de las especies tolerantes que se encuentran en el sotobosque. Esta estrategia ha sido probada en Nueva Zelandia a partir de bosques de pino radiata.

En la mayoría de los casos, las plantaciones forestales se establecen con el propósito de producir madera. En estos casos, cuando alcanzan su rotación comercial, son cosechadas y una parte del carbono que almacenaron se emite a la atmósfera y otra parte queda capturada por un período largo en los productos, como construcciones, muebles y otros. También existe una fracción del carbono que queda fijada permanentemente en el suelo.

Para efectos de evaluar su captura de carbono, se considera que una masa de plantaciones con objetivo productivo, que se encuentra en régimen la cosecha y esta iguala la reforestación, presenta una captura incremental anual marginal a nula. Sin embargo, esa masa forestal puede contener un alto nivel de stock de carbono secuestrado a lo largo de los años, antes de llegar al equilibrio. (Figura $\mathrm{N}^{\circ} 2$ ).

Iniciativas que expandan la superficie de plantaciones por sobre el nivel actual (una ley de fomento, por ejemplo), promoverán capturas de carbono incrementales a tasas altas (Cuadro $\mathrm{N}^{\circ}$ 6) mientras se van estableciendo las nuevas plantaciones. Una vez que estas lleguen nuevamente al equilibrio entre plantación y corta, se tendrá un nivel de stock de carbono capturado más alto que el actual, pero se reducirán o harán nulas nuevamente las capturas adicionales anuales.

Las plantaciones forestales han sido controvertidas y se las critica señalando que usan demasiada agua y tienen impactos negativos en el ciclo hidrológico, que almacenan menos stock de carbono que los bosques nativos, que contribuyen a la erosión, que favorecen la ocurrencia de incendios forestales y que empobrecen los territorios en que se encuentran. Existen, sin embargo, 
elementos fundados que permiten formarse una opinión más balanceada.

El uso de agua en los bosques tiende a ser proporcional a la biomasa que generan. Al ser más productivas de biomasa que otros bosques, las plantaciones en general deberían utilizar más agua que los bosques naturales por unidad de superficie,

Sin embargo, el aspecto clave es cuánta agua utilizan por unidad de madera producida, donde se tiene la situación inversa (Figura № 1). También es necesario analizar el uso de agua por tonelada de $\mathrm{CO}_{2}$ capturada, ya que, al ser proporcional a la biomasa, las plantaciones de rápido crecimiento deberían tener una eficiencia similar de uso de agua al capturar $\mathrm{CO}_{2}$ que la que tienen para la producción de madera.

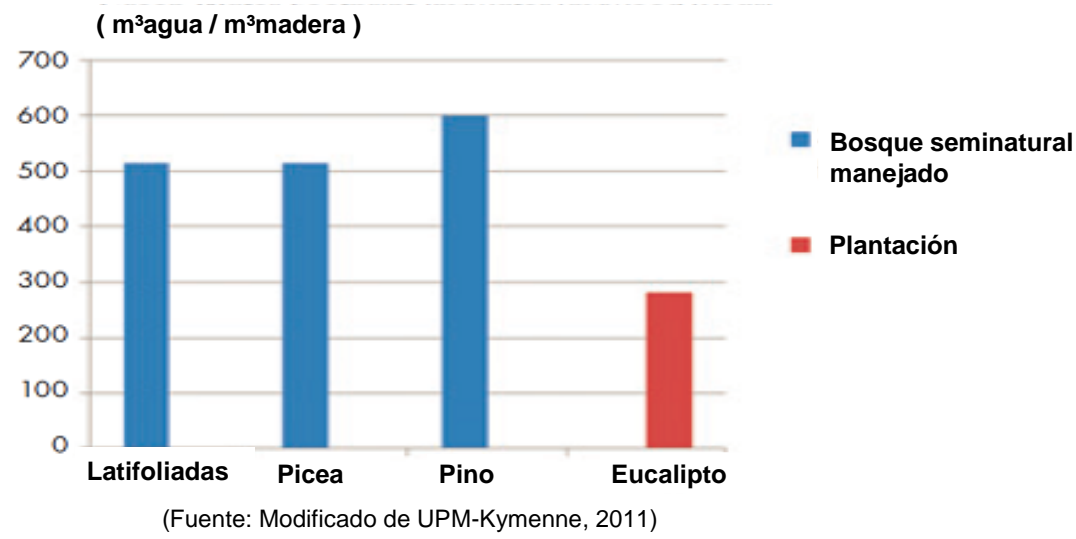

Figura $N^{\circ} 1$

HUELLA AGUA VERDE POR MADERA PRODUCIDA

El análisis del uso del agua es complejo y la comparación entre ambos tipos de bosques varía según el tipo de cuenca (grande o pequeña), la época del año, las edades de los bosques nativos y plantados, teniéndose conclusiones variables para ambos tipos de bosques (Prado, 2015, en base a Bren y Hopmans, 2007), (Otero et al., 1994), (Pizarro et al., 2019).

La mayoría de los estudios que se citan para fundar la noción de que las superficies de bosques nativos mantienen más stock de carbono que las plantaciones (Armesto et al, 2009; Keith et al., 2009; Stolpe et al., 2010; Urrutia Jalabert et al., 2015), son utilizados comparando bosques nativos longevos en equilibrio con plantaciones que no han alcanzado dicho equilibrio, algunas en la mitad de su ciclo de vida. No hay evidencia concluyente para pensar que sitios similares en equilibrio produzcan muy distinto volumen de biomasa entre distintos bosques.

Los bosques plantados han sido la gran herramienta para combatir la erosión, particularmente en terrenos degradados por la agricultura. Fueron la respuesta, desde el tiempo de Federico Albert, para este flagelo. Más del $90 \%$ de ellas se establecieron en terrenos con distintos grados de erosión en Chile.

Existe evidencia que un suelo bajo plantaciones de pino radiata presenta mejores condiciones que un suelo vecino de uso agrícola y que los rendimientos agrícolas (trigo) sobre suelos cosechados de pino radiata no presentan disminuciones (Toro, 2008). 
La biomasa producida por los bosques de todo tipo es combustible. Alrededor de $50 \%$ de la madera del mundo se usa para energía. Así, es razonable pensar que las plantaciones desarrolladas para producir alto volumen de biomasa por hectárea, conllevan un riesgo mayor de incendios que bosques de menor volumen o con estructuras más heterogéneas.

Sin embargo, las diferencias entre bosques no son tan sustanciales, existen especies nativas, como avellano, laurel u olivillo (Peña, 2014), más combustibles que especies industriales, como eucaliptos. De hecho, en Chile, en los últimos 34 años del promedio de las superficies incendiadas, incluyendo los grandes siniestros del 2017, solamente un $28,1 \%$ corresponde a plantaciones y el resto a vegetación natural y bosques nativos (CONAF, 2019).

En los grandes incendios del Amazonas (agosto - septiembre 2019), varios millones de hectáreas en Brasil, Bolivia y Paraguay, la presencia de plantaciones es muy poco significativa, siendo la mayoría de los bosques quemados correspondientes a selva húmeda.

Los riesgos de incendio se pueden gestionar en las plantaciones mediante silvicultura preventiva y políticas adecuadas de prevención.

La industria forestal basada en bosques plantados es un importante generador de actividad económica y empleo a nivel nacional, y especialmente a nivel de las regiones forestales. Está entre los diez sectores de mayor efecto multiplicador en la economía, superando a la construcción y al comercio, y las comunas más forestales han reducido la pobreza a tasas similares a las agrícolas en los últimos 30 años (UNTEC - Universidad de Chile, 2014; Centro EARTH Universidad Adolfo Ibáñez, 2017).

En un estudio sociológico desarrollado por Nazif y Cabañas (2014) se demostró que campesinos y miembros de comunidades no vinculan pobreza rural con plantaciones forestales.

\subsection{Bosque Nativo}

\subsubsection{Manejo de Bosque Nativo}

El manejo del bosque nativo chileno a gran escala es aún una tarea pendiente y tiene buen pronóstico dados los muchos antecedentes científicos y prácticos que orientan para su éxito.

En la actualidad las intervenciones se han concentrado básicamente en fragmentos de los bosques de crecimiento secundario (renovales) de los tipos forestales Roble-Rauli-Coigue (1,65 millones de hectáreas) y Coigue-Rauli-Tepa (0,85 millones de hectáreas), a través de raleos, y en los bosques del tipo Lenga (3,63 millones de hectáreas), a través de cortas de protección. Existen otros tipos forestales, como el Siempreverde y el Esclerófilo, con potencial de desarrollo.

La condición de crecimiento secundario tiene su origen en la masiva regeneración en monte bajo (brotes de tocón) y monte alto (semilla) después de los grandes incendios que arrasaron gran parte de los bosques primarios de las cordilleras de Los Andes y de La Costa. Actualmente su estrato superior se conforma dominantemente por las especies del género Nothofagus y el inferior por especies arbóreas tolerantes, dando origen a bosques multiespecíficos con dos marcados estratos bastante coetáneos.

Estos bosques, por las condiciones edafoclimáticas donde se ubican, presentan un gran potencial de crecimiento, siempre y cuando se los maneje desde edad temprana. Esto debiera hacerse intensamente entre los cinco y 20 años (podas y raleos) y posteriormente con raleos más suaves hasta llegar al diámetro objetivo para su cosecha (35 a $55 \mathrm{~cm}$ ).

Un ejemplo de situación, donde se podrían implementar cortas de regeneración en el corto plazo para iniciar un manejo temprano con selección de árboles futuro y podas que apunten a la producción de maderas finas de alta calidad, se da en más de 800 mil hectáreas de renovales 
del tipo forestal Roble-Rauli-Coigue (Cuadro №2).

Sin embargo, las avanzadas edades de estos dificultan respuestas significativas a los raleos, por lo cual se debe optar por la creación de un nuevo bosque intervenido con silvicultura oportuna. Los diámetros promedio de los árboles de estos rodales permiten obtener una cierta porción de trozas aserrables, lo que ayudaría a financiar las intervenciones de regeneración y cosecha que deben generar un bosque rejuvenecido y modelado tempranamente por la silvicultura.

En el caso de los bosques de lenga, las cortas que se están realizando abren espacios donde masivamente regenera la especie, entregando la posibilidad de intervenciones tempranas en unas 700 mil hectáreas de bosque adulto (Martin et al., 2014), que apuntan a obtener árboles más sanos que en la generación anterior y así un aumento en su aprovechamiento potencial.

\section{Cuadro $\mathrm{N}^{\circ} 2$ \\ SUPERFICIE POTENCIALMENTE APTA PARA CORTAS DE REGENERACION EN TIPO FORESTAL ROBLE-RAULI-COIGUE}

\begin{tabular}{|c|c|c|c|c|c|}
\hline \multirow[t]{2}{*}{ REGION } & \multicolumn{5}{|c|}{$\begin{array}{c}\text { Superficie } \\
\text { (ha) }\end{array}$} \\
\hline & $\mathrm{DMC}>50 \mathrm{~cm}$ & $\mathrm{DMC} \leq 15 \mathrm{~cm}$ & DMC 15 a $25 \mathrm{~cm}$ & $\mathrm{DMC}>25 \mathrm{~cm}$ & Total \\
\hline Maule & 6.532 & 1.331 & 49.700 & 29.967 & 87.530 \\
\hline Bio Bio / Ñuble & 9.799 & 4.606 & 210.397 & 64.300 & 289.102 \\
\hline Araucanía & 4.682 & 12.615 & 169.779 & 25.386 & 212.462 \\
\hline Los Ríos & 2.899 & 15.513 & 119.060 & 8.010 & 145.482 \\
\hline Los Lagos & 5.225 & 13.047 & 121.376 & 12.500 & 152.148 \\
\hline Total & 29.137 & 47.112 & 670.312 & 140.163 & 886.724 \\
\hline
\end{tabular}

DMC: Diámetro medio cuadrático

(Fuente: INFOR, 2018)

\subsubsection{Sustentabilidad del Bosque Nativo con y sin Producción Maderera}

El manejo sustentable del bosque nativo se fundamenta en tres pilares, que son el económico, el social y el ambiental. Tres funciones clave que le entregan al bosque un valor para la sociedad desde la perspectiva de la producción maderera y los servicios ambientales.

Para los propietarios, la puesta en valor del recurso a través de la silvicultura implica poder vender sus productos a precios que permitan dar continuidad al manejo en el largo plazo. Les permite también apreciar que el aprovechamiento de su recurso cumpliendo con los altos estándares ambientales que la Ley de Recuperación del Bosque Nativo exige es una actividad económica atractiva y lleva a proteger el bosque y asegurar su existencia.

Manejar el bosque para entregar exclusivamente servicios ambientales solo se hace factible cuando la sociedad está dispuesta a pagar por esto. En Chile existe hasta el momento un solo ejemplo de esto, impulsado por INFOR, donde se han activado instituciones dispuestas a este pago para garantizar la calidad del agua en la cuenca de Ancud. Se podría decir que es un primer paso, aunque dista bastante de un pago organizado a través de los consumidores directos.

Para que el pago por servicios ambientales se instale masivamente en la sociedad aún falta bastante por hacer para su convencimiento, más aún cuando en la sociedad existen una serie de otras necesidades insatisfechas, tales como salud, previsión, educación, vivienda, infraestructura caminera y otras. 


\begin{abstract}
Sustentabilidad
Después de severas destrucciones de bosques en el centro de Europa ya en el siglo 18 $y$, en consecuencia, de la falta de materia prima, se inician los primeros pasos para el manejo sustentable de los bosques.

Se reconoce a Hans Carl von Carlowitz como el fundador en el año 1713 del principio de la "sustentabilidad" descrito en su obra "Sylvicultura Oeconomica", donde define que no se debe cosechar más de lo que se obtiene a través del crecimiento que se logra por regeneración planificada ${ }^{6}$. El científico forestal Georg Ludwig Hartig publica en 1791 los instructivos para una silvicultura sustentable ${ }^{7}$. Sería entonces Carlowitz y Hartig los fundadores del concepto "Nachhaltigkeit", que se puede traducir como "sustentabilidad" y que nace como el principio para el manejo forestal.

Este concepto se fundamente en tres pilares, que son el económico, el social y el ambiental. Para que estos funcionen los bosques deben ser estables frente a factores internos, como pueden ser plagas, y externos, como son los temporales, sequias y otros.

Para poder dar esta estabilidad se ofrece la silvicultura como la herramienta que da garantía para que los bosques puedan mantener sus funciones en el largo plazo. Se debe entender entonces que la sustentabilidad de los bosques es la base de la ingeniería forestal.
\end{abstract}

\title{
2.3.3. Contribución del Bosque Nativo al Medio Ambiente Local y Global, Servicios Ecosistémicos
}

El bosque nativo históricamente fue el pilar de la producción maderera. Durante la primera mitad del siglo 20 , y hasta mediados de ese siglo explotaciones sin criterio de manejo sustentable y grandes roces para habilitar terrenos agropecuarios mermaron significativamente las reservas madereras de estos bosques. Esto no significa que su potencialidad haya desaparecido, por lo cual existe la Ley de Recuperación del Bosque Nativo, cuya función es justamente recuperar lo perdido a través de esquemas de manejo sustentables, ayudados por incentivos estatales. Sin embargo, los bajos montos disponibles para las distintas actividades de manejo han llevado a un bajo impacto de la ley, por lo cual se está trabajando en una nueva propuesta que considere costos realistas que permita efectivamente lograr el objetivo.

El manejo sustentable, que es el principio de la ley, debe incluir los servicios ecosistémicos como parte fundamental, entendiendo que consisten de la multitud de beneficios que la naturaleza aporta a la sociedad ${ }^{8}$, haciendo posible la vida humana, por ejemplo al proporcionar alimentos y agua limpia, al regular las enfermedades y el clima, al apoyar la polinización de los cultivos y la formación de suelos, y al ofrecer beneficios recreativos, culturales y espirituales.

Los servicios ambientales pueden ser clasificados en grupos que resumen las principales funciones ecosistémicas (Villalobos, 2007):

Provisión: Bienes producidos o proporcionados por los ecosistemas, como alimentos, agua, combustible, fibras, recursos genéticos y medicinas naturales.

\footnotetext{
${ }^{6}$ https://www.bmel.de/DE/Wald-Fischerei/Forst-Holzwirtschaft/_texte/Carlowitz-Jahr.html

${ }^{7}$ https://de.wikisource.org/wiki/Georg_Ludwig_Hartig

8 (http://www.fao.org/ecosystem-services-biodiversity/es/)
} 
- Regulación: Servicios obtenidos de la regulación de los procesos ecosistémicos, como la calidad del aire, regulación de clima, regulación de agua, purificación de agua, control de erosión, regulación de enfermedades humanas, control biológico, mitigación de riesgos.

- Cultural: Beneficios no materiales que enriquecen la calidad de vida, tales como la diversidad cultural, los valores religiosos y espirituales, conocimiento tradicional y formal, inspiración, valores estéticos, relaciones sociales, sentido de lugar, valores de patrimonio cultural, recreación y ecoturismo.

- Soporte: Servicios necesarios para producir todos los otros servicios, incluida la producción primaria, la formación del suelo, la producción de oxígeno, retención de suelos, polinización, provisión de hábitat, reciclaje de nutrientes, otros.

De estos grupos se pueden obtener cuatro servicios (Villalobos, 2007):

- Mitigación de emisiones de gases de efecto invernadero (reducción, secuestro, almacenamiento).

- $\quad$ Protección de la calidad del agua (diferentes usos).

- Protección de la biodiversidad (uso científico, farmacéutico, mejoramiento genético).

- $\quad$ Protección contra desastres naturales

Existen bosques, en los que se aplica silvicultura y extracción maderera, que proveen servicios ecosistémicos y otros en los cuales no se hace extracción maderera, lo cual dependerá de las condiciones del sitio y su propósito en particular.

En Chile existe un ejemplo de pago por servicios ecosistémicos, el ya mencionado de la cuenca de abastecimiento de agua en Ancud (Cabrera, 2007; Cabrera et al., 2007).

\subsubsection{Bosque Nativo, Perfil de Crecimiento y Potencial de Captura de $\mathrm{CO}_{2}$}

Los bosques nativos de Chile según el Catastro Vegetacional (CONAF, CONAMA, BIRF, 2017) cubren una superficie de 14,6 millones de hectáreas, de la cual el $41,9 \%$ corresponde a bosque nativo adulto, un $31,6 \%$ a renovales, un $7,3 \%$ a bosque adulto-renoval y un $19,1 \%$ a bosques achaparrados (Cuadro $\mathrm{N}^{\circ} 3$ ).

\section{Cuadro $\mathrm{N}^{\circ} 3$}

SUPERFICIE DE BOSQUE NATIVO EN CHILE SEGÚN ESTRUCTURA

\begin{tabular}{|r|r|r|r|r|}
\hline Bosque Adulto & \multicolumn{1}{|c|}{ Renoval } & Adulto-Renoval & \multicolumn{1}{c|}{ Achaparrado } & \multicolumn{1}{c|}{ Total } \\
\hline 6.131 .595 & 4.629 .909 & 1.080 .794 & 2.791 .482 & 14.633 .780 \\
\hline
\end{tabular}

(Fuente: CONAF, CONAMA, BIRF, 2017)

El bosque nativo adulto se podría considerar en una situación que en la literatura se describe como "en equilibrio o steady state", lo que significa que se encuentra en una constante situación de regeneración, muerte y descomposición no existiendo crecimiento en el ecosistema en su totalidad. Este concepto teórico es bastante aceptado, existiendo variaciones dentro los sistemas dinámicos de estos bosques. Su estructura cambia en el tiempo, así como las especies durante las sucesiones, influenciado por eventos como temporales, fuego u otros (Frelich, 2016). 
Para este tipo de bosques en Chile estos fenómenos están documentados para aquellos de especies de Nothofagus del centro sur del país (Veblen y Ashton, 1978; Veblen et al., 1979; Veblen et al., 1980; Veblen et al., 1981).

También para los bosques de lenga en la zona austral existen numerosos estudios que permiten entender la dinámica de estos bosques (Bava, 1999; Schmidt y Urzúa, 1982; Álvarez y Grosse, 1978).

Esta situación se repite en otros bosques como son los de la selva amazónica, donde se describe para la zona central de esta el mosaico de parches en distintas etapas de la sucesión en el marco de un desarrollo en equilibrio (Chambers, et al., 2012).

Si bien podría ser discutible el concepto de perfecto equilibrio sin crecimiento a nivel del bosque adulto total, se asume que la captura de carbono se contrarresta con la emisión por muerte de los individuos que caen por viejos. Lo mismo podría asumirse para los bosques achaparrados.

Distinta es la situación de los renovales, que se encuentran en una etapa donde el crecimiento de los árboles supera ampliamente al decrecimiento que se produce por la muerte de árboles que ocurre de manera esporádica. Esto a pesar de que la mayoría de los renovales, al menos los del tipo forestal Roble-Raulí-Coigue y Coigue-Raulí-Tepa, se encuentran ya fuera del rango de su crecimiento óptimo (Grosse, 2009). Para estos bosques entonces la captura de carbono marginal es positiva.

El bosque nativo adulto renoval requiere de un análisis más profundo que está pendiente. Su categorización insinúa que aún no se encuentra en una situación de equilibrio y aporta captura de carbono, ya que su crecimiento supera al decrecimiento probablemente de manera leve.

Al hacerse la pregunta respecto de cuán expandible es el área para ser plantada con árboles, el estudio de Beltrán (2013) arroja una superficie potencial de cerca de 2,6 millones de hectáreas. No obstante, para poder responder con más exactitud, se debe tener claridad a qué uso está sometida esta superficie en la actualidad y qué deterioro presenta el suelo. Lo más probable es que en la medida que no presente erosión o solo grados ligeros de ella, esté ocupada para pastoreo o agricultura extensiva, llegando al 49,8 \%, lo que hace difícil que los propietarios deseen cambiar hacia el uso forestal. Del 50,2\% restante (1.290.631 ha) unas 625 mil hectáreas presentan erosión moderada, 428 mil hectáreas erosión severa y 236 mil hectáreas erosión muy severa (Cuadro $\mathrm{N}^{\circ} 4$ ).

\section{Cuadro $\mathrm{N}^{\circ} 4$ \\ CATEGORIA DE EROSION POR REGION}

\begin{tabular}{|c|c|c|c|c|c|c|c|c|}
\hline \multirow{3}{*}{\begin{tabular}{|l} 
Región \\
Categoría Erosión \\
\end{tabular}} & \multicolumn{6}{|c|}{ Superficie } & \multirow{2}{*}{\multicolumn{2}{|c|}{ Total }} \\
\hline & O'Higgins & Maule & $\begin{array}{l}\text { Bio Bio } \\
\text { Ñuble }\end{array}$ & Araucanía & $\begin{array}{l}\text { Los Ríos } \\
\text { Los Lagos }\end{array}$ & Aysén & & \\
\hline & \multicolumn{6}{|c|}{ (ha) } & (ha) & $(\%)$ \\
\hline Muy Severa & 6.304 & 20.162 & 4.365 & 42.886 & 9.079 & 154.118 & 236.914 & 9,2 \\
\hline Severa & 60.699 & 101.042 & 27.062 & 114.619 & 22.682 & 101.687 & 427.791 & 16,7 \\
\hline Moderada & 154.883 & 96.781 & 109.653 & 80.247 & 60.611 & 123.751 & 625.926 & 24,4 \\
\hline Ligera & 16.379 & 28.890 & 69.553 & 65.173 & 77.869 & 43.398 & 301.262 & 11,7 \\
\hline No Aparente & 17.349 & 10.574 & 70.860 & 53.185 & 80.411 & 178.116 & 410.495 & 16,0 \\
\hline Sin & 20.323 & 26.108 & 107.762 & 181.991 & 59.026 & 31.952 & 427.162 & 16,7 \\
\hline Otros Usos & 11.090 & 10.250 & 18.997 & 7.320 & 19.535 & 49.519 & 116.711 & 4,6 \\
\hline Sin Clase & 1.233 & 344 & 2.285 & 264 & 4.784 & 514 & 9.424 & 0,4 \\
\hline Áreas de Exclusión & - & - & & 4.585 & 4.479 & -1 & 9.064 & 0,4 \\
\hline Total & 288.260 & 294.151 & 410.537 & 550.270 & 338.476 & 683.055 & 2.564 .749 & 100,0 \\
\hline
\end{tabular}


En la medida que el suelo está más erosionado y distante de su condición original se hace más difícil y de mayor costo la plantación exitosa con especies nativas.

Probablemente los mejores resultados potencialmente se puedan conseguir en los suelos que pudiesen estar disponibles bajo la condición de erosión moderada, en zonas de pluviometría abundante y períodos estivales de sequía corta, para especies nativas capaces de colonizar, como son raulí, roble y el híbrido entre ambas.

Estos suelos corresponden básicamente a las regiones de la Araucanía y Los Ríos/Los Lagos y sumarían unas 140 mil hectáreas, siempre y cuando los propietarios quisieran darle un uso forestal con especies nativas.

En las regiones al norte de La Araucanía y al sur de Los Ríos/Los Lagos también existe superficie potencialmente forestable con especies nativas.

Hacia el norte los períodos estivales cada vez más secos y largos dificultan y encarecen el éxito el éxito de plantaciones con especies como roble y raulí y podría requerir cambiar a algunas especies del bosque esclerófilo, como quillay, peumo, litre y otras.

Hacia el sur, en Aysén, habría que plantearse la expansión de los bosques de lenga, para lo cual la exclusión del ganado en orillas de bosque, mediante la instalación de cercos, y la plantación complementaria podría ser un método promisorio.

En situaciones de alto deterioro de suelos habría que considerar no partir por plantar árboles, sino especies vegetales de una etapa anterior de la sucesión vegetacional.

En consecuencia, si bien existe una extensa superficie que requiere ser recuperada de la erosión, con cerca de 1,6 millones de hectáreas desde ligera a muy severa, se debe elegir muy bien que especie plantar de acuerdo a razones técnicas y las necesidades del propietario.

Otro factor muy importante es el costo de establecimiento, el cual a medida que las condiciones del sitio son más complejas se eleva, debido a que hacen necesarias técnicas de establecimiento más intensas, pudiendo llegar a más de 3.500 US\$/ ha.

\section{CAPTURA DE CARBONO: COSTOS SOCIALES Y PRIVADOS}

El objetivo planteado en Chile de lograr que el país sea carbono neutral en 2050 requerirá esfuerzos, tanto en el campo de reducción de emisiones como en el de mantener e incrementar la capacidad de captura de $\mathrm{CO}_{2}$, y es fundamental que esta meta se logre de la forma más eficiente posible, en términos de no sacrificar la satisfacción de otras grandes necesidades de la sociedad, más allá del mínimo indispensable para obtener el resultado deseado.

Las discusiones y planteamientos hasta el momento se han centrado en consideraciones físicas, como características de crecimiento y captura de $\mathrm{CO}_{2} \mathrm{O}$ beneficios ambientales de determinadas especies forestales, pero es indispensable analizar las consideraciones de eficiencia socioeconómica de las distintas opciones para contribuir a generar una estrategia que sea ambiental, social y económicamente fundada y responsable.

\subsection{Valorización de Alternativas Forestales de Captura de Carbono}

Con el objeto de ilustrar comparativamente los niveles de costo y cantidad de $\mathrm{CO}_{2}$ capturado para distintas alternativas de plantaciones forestales, se utilizó el modelo de cálculo del Sistema Chileno de Certificación de Manejo Forestal Sustentable (CERTFOR). 
Se analizaron solamente alternativas de aumento de superficie de cobertura (forestación o regeneración), por lo que no se incluyeron alternativas de mejoramiento vía manejo de bosques existentes.

\section{Alternativas}

1. Forestación con pino radiata, régimen de producción

2. Forestación con Eucalyptus globulus, régimen de producción

3. Forestación con Eucaliptus nitens, régimen de producción

4. Forestación con pino radiata, sumidero permanente

5. Forestación con Eucaliptus nitens, sumidero permanente

6. Forestación con especies nativas, régimen de producción

7. Forestación con especies nativas, sumidero permanente

8. Forestación especies nativas alto rendimiento, silvicultura intensiva, régimen producción

9. Regeneración asistida especies nativas, sumidero permanente

En la Figura $\mathrm{N}^{\circ} 2$ se muestra un perfil simplificado de la captura de carbono de plantaciones en régimen de producción, donde se alcanza un nivel de captura de $\mathrm{CO}_{2}$ hasta la edad de rotación y luego se mantiene en virtud de sucesivas superficies anuales que llegan a la edad de cosecha.

Este perfil representa los casos 1, 2 y 3 de plantaciones con exóticas, y el 8 de plantaciones con nativas.

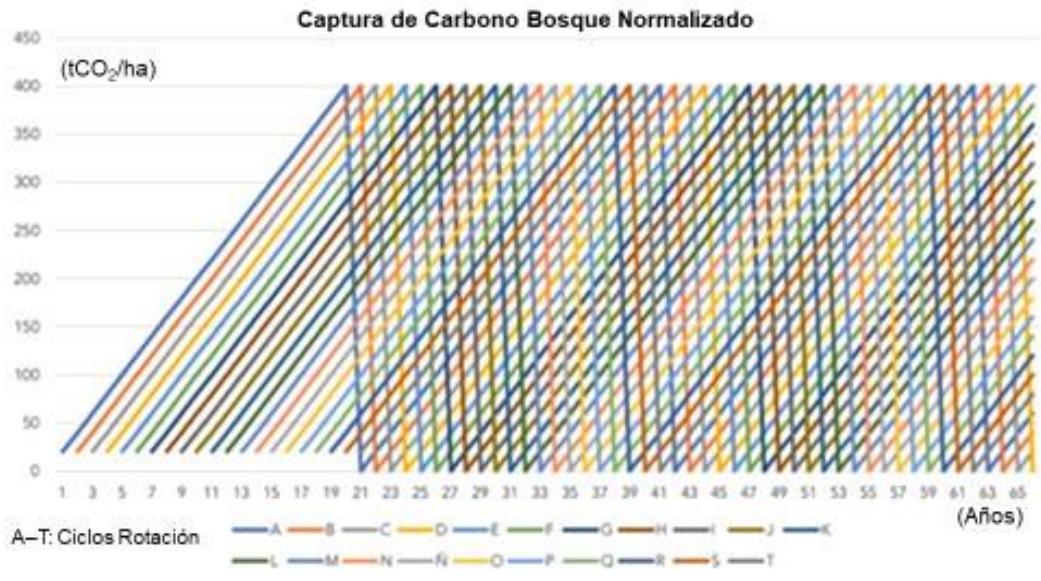

Figura $N^{\circ} 2$

CAPTURA DE CARBONO DE PLANTACIONES EN REGIMEN

En la Figura $N^{\circ} 3$ se muestra un perfil de plantaciones en régimen de producción caso 1 (línea punteada) y un perfil de forestación nativa como sumidero permanente, como en el caso 7.

Se aprecia que la acumulación de carbono en la forestación nativa tarda más en 
incrementarse, pero luego supera el nivel de equilibrio de las plantaciones, dado que no produce madera sino solo acumula carbono. En el largo plazo, el perfil de sumidero permanente alcanza un nivel de equilibrio.

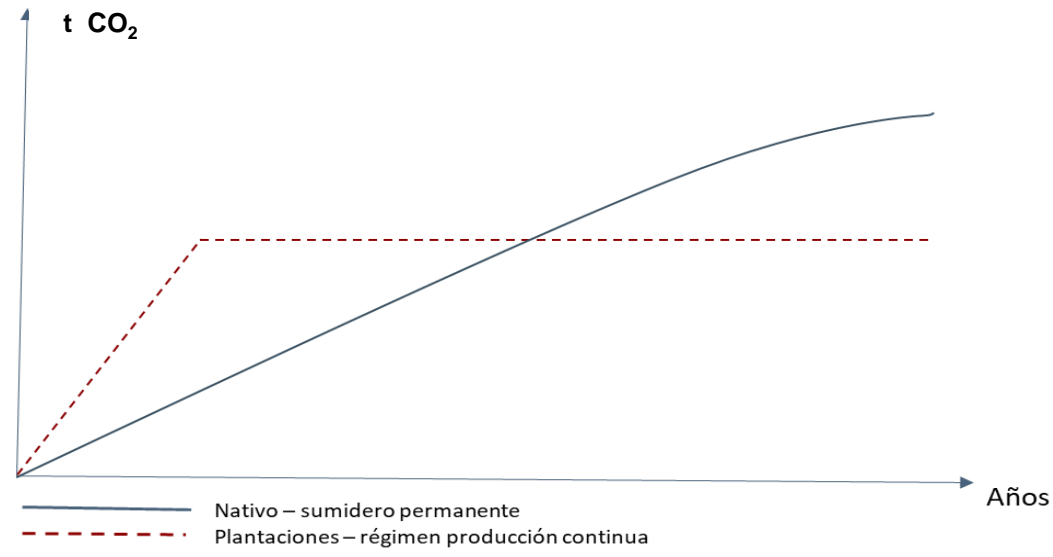

Figura $\mathbf{N}^{\circ} 3$

PLANTACION PINO RADIATA EN REGIMEN Y FORESTACION NATIVA SUMIDERO PERMANENTE

En la Figura $\mathrm{N}^{\circ} 4$ se muestra un perfil simplificado de captura de $\mathrm{CO}_{2}$ de forestación nativa con régimen de producción parcial, caso 6 , donde se extrae una fracción del volumen. Este perfil acumulará menor cantidad de $\mathrm{CO}_{2}$ que el sumidero permanente, pero aportará producción maderera.

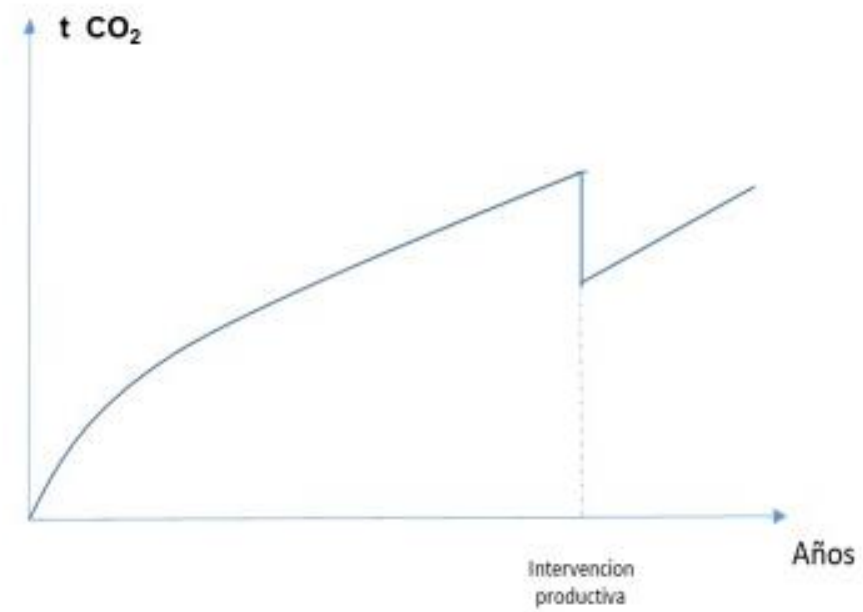

Figura $\mathrm{N}^{\circ} 4$

REGIMEN DE PRODUCCION PARCIAL EN PLANTACION CON ESPECIES NATIVAS 


\subsection{Enfoque del Análisis y Supuestos del Modelo}

El objetivo del análisis es comparar el nivel de precio de la tonelada de $\mathrm{CO}_{2}$ capturada que sería necesario para obtener una rentabilidad igual al costo social del capital (se consideró $6 \%$ ), en cada alternativa analizada. Se puede asimilar a un indicador del "nivel de sacrificio" que demanda a la sociedad optar por una determinada alternativa. Los principales supuestos del modelo son:

- Horizonte de evaluación: 100 años.

- Plantaciones en régimen de producción emiten todo el carbono capturado a la cosecha, y "pagan" su valor. Se reforestan al año siguiente de la cosecha.

- $\quad$ Plantaciones sumidero permanente no se cosechan en el horizonte.

- $\quad$ Se representa el valor alternativo de la tierra a través de una anualidad ("arriendo").

- Forestaciones con especies nativas en régimen de producción se intervienen manteniendo la cobertura, suponiendo extracción del 30\% del volumen. Se consideran parámetros de Roble - Raulí - Coigue.

- Se incluye un caso de forestación nativa con silvicultura intensiva en régimen de producción con cosecha total y reforestación.

- Regeneración asistida consiste en cercar sectores aledaños a bosques nativos, excluyendo el uso ganadero, y en el establecimiento de 300 plantas/ ha.

- Parámetros de captura de $\mathrm{CO}_{2}$ corresponden a los utilizados por INFOR en los cálculos entregados al Ministerio de Medio Ambiente.

\subsection{Principales Resultados}

Los principales resultados son resumidos en los Cuadros $\mathrm{N}^{\circ} 5 \mathrm{y} \mathrm{N}^{\circ} 6$.

\section{RESULTADOS POR ALTERNATIVA DE MANEJO}

\begin{tabular}{|c|c|c|c|c|c|c|c|}
\hline \multirow[b]{2}{*}{ Alternativa } & \multicolumn{2}{|c|}{ Resultados } & \multicolumn{5}{|c|}{ Parámetros } \\
\hline & $\begin{array}{c}\text { Precio } \\
\text { Mínimo } \\
\text { (US\$/tCOz) }\end{array}$ & $\begin{array}{c}\text { Captura } \\
\text { Permanente } \\
\text { (tCO//ha) }\end{array}$ & $\begin{array}{l}\text { Rotación } \\
\text { (Años) }\end{array}$ & $\begin{array}{c}\text { Precio } \\
\text { Medio } \\
\text { Madera en } \\
\text { Pie } \\
\left(\mathrm{US} \$ / \mathrm{m}^{3}\right)\end{array}$ & $\begin{array}{c}\begin{array}{c}\text { Crecimiento } \\
\text { Medio }\end{array} \\
\text { (m³/ha/año) }\end{array}$ & $\begin{array}{c}\text { Contenido } \\
\mathrm{CO} 2 \\
\left(\mathrm{t} / \mathrm{m}^{3}\right)\end{array}$ & $\begin{array}{l}\text { Costo } \\
\text { Establecimiento } \\
\text { (US\$/ha) }\end{array}$ \\
\hline
\end{tabular}

\begin{tabular}{|c|c|c|c|c|c|c|c|}
\hline Forestación Pr reg. producción & 5,8 & 221 & 22 & 27 & 15,35 & 1,31 & 1.500 \\
\hline Forestación Eg reg. producción & 9,9 & 200 & 13 & 20 & 15,61 & 1,97 & 1.500 \\
\hline Forestación En reg. producción & $0,0^{\star}$ & 332 & 13 & 15 & 30,62 & 1,67 & 1.500 \\
\hline Forestación Pr sumidero permanente & 11,32 & 1.000 & 100 & 0 & 15,35 & 1,31 & 1.500 \\
\hline Forestación En sumidero permanente & 6,27 & 1.000 & 100 & 0 & 30,62 & 1,67 & 1.500 \\
\hline Forestación Nat reg. producción & 49,4 & 480 & 40 & 22 & 4,57 & 1,50 & 3.000 \\
\hline Forestación Nat sumidero permanente & 43,8 & 686 & 100 & 0 & 4,57 & 1,50 & 3.000 \\
\hline Forestación Nat produccion silv. intensiva & 22,7 & 270 & 30 & 30 & 12,00 & 1,50 & 3.500 \\
\hline Reg. Asist. Nat sumidero permanente & 35,5 & 686 & 100 & 0 & 4,57 & 1,50 & 2.000 \\
\hline
\end{tabular}

Costo social del capital: $6 \%$

Valor del suelo: US\$ 100/año Pr: Pino radiata En: Eucalyptus nitens Eg: Eucalyptus globulus Nat: Nativas

Administración/seguros: US\$50/ha/año casos producción y US\$30/ha/año casos sumidero permanente

-(*) Forestación En reg. Producción: Con los parámetros utilizados arroja VPN positivo con tasa de costo de capital $6 \%$, por lo que el carbono capturado no tiene un costo adicional para la sociedad. 
Cuadro $\mathrm{N}^{\circ} 6$

PLANTACIONES: TASA DE CAPTURA UTILIZADAS

\begin{tabular}{|l|c|c|c|}
\hline Alternativa & $\begin{array}{c}\text { Crecimiento } \\
\text { Medio } \\
\left(\mathbf{m}^{\mathbf{3}} / \mathbf{h a} / \mathbf{a n ̃ o}\right)\end{array}$ & $\begin{array}{c}\text { Contenido } \\
\mathbf{C O}_{\mathbf{2}} \\
\mathbf{( t / \mathbf { m } ^ { 3 } )}\end{array}$ & $\begin{array}{c}\text { Captura } \\
\text { Anual Media } \\
(\mathbf{t C O} / \mathbf{a n ̃ o})\end{array}$ \\
\hline Forestación $\mathrm{Pr}$ & 15,35 & 1,31 & 20,11 \\
\hline Forestación $\mathrm{Eg}$ & 15,61 & 1,97 & 30,75 \\
\hline Forestación En & 30,62 & 1,67 & 51,14 \\
\hline
\end{tabular}

\subsection{Comentarios}

Desde el punto de vista de los costos para la sociedad por tonelada de $\mathrm{CO}_{2}$ capturado, las plantaciones exóticas en régimen de producción muestran los valores más reducidos, donde destaca especialmente el Eucalyptus nitens, que es capaz de rentar el costo del capital ( $6 \%$ en este caso) sin requerir aporte alguno de valor del carbono. Con respecto a las especies nativas, el menor costo de captura de carbono también se logra con plantaciones manejadas intensivamente en régimen productivo y con cosecha a tala rasa.

En la discusión pública a menudo se compara plantaciones exóticas con bosque nativo en su capacidad de captura de carbono, pero asumiendo que las primeras serán cortadas para producción maderera y los segundos no. En verdad entonces, no se trata de una comparación entre especies como equivocadamente se presenta, sino entre dos regímenes distintos; producción maderera versus régimen de sumidero permanente. Para profundizar este análisis, se compararon los costos de captura como sumideros permanentes en plantaciones exóticas (casos 4 y 5 ) con forestaciones nativas (casos 7 y 9). Se puede apreciar que los costos en las primeras son considerablemente más bajos que en las segundas, lo que sustenta la idea de considerar entre las posibles medidas de mitigación la creación de sumideros permanentes de especies exóticas.

Como contraparte a sus menores costos de captura de $\mathrm{CO}_{2}$, las plantaciones en régimen de producción (tanto especies exóticas como nativas) logran un nivel de stock de $\mathrm{CO}_{2}$ retenido considerablemente inferior a las de régimen de sumidero permanente en el horizonte de evaluación (100 años). También es importante notar que, en los casos de especies nativas de crecimiento lento, estas tardarán períodos más largos en alcanzar niveles de equilibrio; para el ejercicio de cálculo desarrollado, no alcanzaron el tope de $1000 \mathrm{tCO}_{2} /$ ha considerado en el modelo dentro del período de evaluación.

En la comparación entre los casos 6 , forestación nativa convencional con régimen de producción de baja intensidad y 7) forestación nativa convencional sumidero de carbono, el análisis refleja la aparente paradoja de que la opción productiva encarece la captura de carbono respecto a la opción sumidero permanente. La razón es que el precio del carbono que se requiere en estos casos para compensar el costo social del capital es tan alto que supera con creces el posible retorno económico de la producción maderera. Al comparar ambos casos con el caso 8 (con costo de captura de $\mathrm{CO}_{2}$ considerablemente más bajo) de forestación de especies nativas con silvicultura intensiva para usos productivos, se resalta más el fenómeno; que no es inherente a la especie sino al régimen de utilización. La conclusión parece ser que, si se deben cumplir cupos con forestaciones nativas de desarrollo lento y silvicultura tradicional, puede ser la mejor opción en términos de costo marginal de captura de carbono el régimen de sumidero permanente. 
En el ámbito de las especies nativas, los menores costos de captura de $\mathrm{CO}_{2}$ se obtienen en los casos 8 y 9 . El primero, forestación con silvicultura intensiva en régimen de producción, ya se comentó previamente. El segundo se aprecia como la opción más conveniente de captura de $\mathrm{CO}_{2}$ con este tipo de especies, y se trata de fomentar la regeneración de los bosques nativos como sumideros permanentes, excluyendo el uso ganadero en terrenos aledaños y apoyando este proceso con el establecimiento de un número reducido de plantas por hectárea (300 en este caso).

Los factores que favorecen las forestaciones con exóticas en régimen de producción en el ámbito del costo, son su menor inversión en el establecimiento, su mayor tasa de crecimiento volumétrico y el ingreso que significa el valor comercial de la producción. Esto apunta a la conveniencia de incorporar capitales privados mediante políticas de fomento de relativamente bajo costo fiscal, incorporación que permite apalancar fuertemente los recursos fiscales desde el punto de vista del financiamiento. Del mismo modo, también se puede lograr un nivel de apalancamiento (aunque a mayor costo fiscal) en las forestaciones con especies nativas en régimen de producción.

Las fuertes diferencias de valores de costo que se obtienen del análisis refuerzan la idea de que no es adecuado fundar estrategias de captura de carbono solamente en atributos físicos de las distintas especies; es muy relevante considerar los regímenes (de producción maderera o solo captura de $\mathrm{CO}_{2}$ ) de las distintas alternativas y los costos que estas pueden representar para la sociedad.

Conviene recordar que este modelamiento no considera otras externalidades positivas o negativas aparte de los parámetros explícitamente indicados, de modo que es materia de discusión el efecto de dichas externalidades en distintos sentidos, como por ejemplo uso de agua en los territorios, control de la erosión, provisión de servicios ecosistémicos, o valor socioeconómico de los encadenamientos productivos. También se debe destacar que lo aquí analizado responde a casos generales tipo y que, si bien permiten formarse una impresión de los órdenes de magnitud involucrados, queda un amplio espacio para profundizar y ampliar los análisis, ya sea en otras situaciones de régimen o precisando los parámetros de evaluación para territorios, especies o circunstancias distintas.

\section{CONSTRUCCIÓN EN MADERA, RETENCIÓN DE $\mathrm{CO}_{2} \mathrm{Y}$ REEMPLAZO DE MATERIALES EMISORES}

Cada día la construcción con madera se hace más atractiva por sus positivas características en materia de efectos ambientales, por su gran flexibilidad en los diseños, por la rapidez en el armado y el alto nivel de aislación térmica.

"La madera es el único material de construcción cuyo uso ayuda a reducir el $\mathrm{CO}_{2}$ de la atmósfera, contribuyendo de esta manera a mitigar el cambio climático. Esto la convierte en la alternativa constructiva con la más baja huella de carbono"9

El arquitecto canadiense Michael Green, conocido por su sistema constructivo para rascacielos de madera, concluye que la madera es el material ideal para revertir el cambio climático y densificar las ciudades de un modo sustentable.

Green argumenta que el acero representa alrededor del $3 \%$ de las emisiones y el hormigón más del $5 \%$, y que para un edificio de hormigón de 20 pisos las emisiones para fabricar el cemento representan $1.200 \mathrm{tCO}_{2}$, mientras que con la madera se capturan unas $3.100 \mathrm{tCO}_{2}{ }^{10}$

9 https://www.madera21.cl/2757-2/:

$10 \mathrm{https}$ ://www.clarin.com/construccion/madera-rascacielos-sustentabilidad_0_SyOeCytvQI.html). 
Una referencia de una publicación de la revista Journal of Sustainable Forestry indica que la construcción de $1 \mathrm{~m}^{2}$ de piso con madera requiere un 16\% (80mj) de la energía que al hacerlo con acero y un $28 \%$ si se hace con cemento. A su vez emiten un $10 \%$ de $\mathrm{CO}_{2}(4 \mathrm{~kg})$ y un $15 \%$ de $\mathrm{CO}_{2}$, respectivamente ${ }^{11}$.

Coincidente con estas afirmaciones, también otros materiales, como ladrillos y baldosas de cerámica en la construcción, aportan significativamente más gases de efecto invernadero que el uso de madera.

Un ejemplo práctico es el edificio de cinco plantas que House Habitat construyó en el distrito barcelonés de Gracia, donde las emisiones de $\mathrm{CO}_{2}$ resultantes de la fabricación de la estructura de madera fueron cinco veces más bajas que si se hubiera realizado en hormigón, y ocho que en acero, reconociéndose que además la madera es un aislante térmico mucho más eficiente que el hormigón y el acero ${ }^{12}$.

Por lo visto anteriormente, fomentar la construcción en madera puede ser una política de alto impacto en la mitigación del cambio climático, tanto por el secuestro de carbono por largos períodos como por el efecto del reemplazo de otros materiales de construcción cuyos procesamientos son altamente emisores de gases de efecto invernadero.

Las políticas forestales que busquen tener impacto de mitigación de cambio climático deben entonces preocuparse no solo de la captura de carbono, sino también de la producción ecoeficiente de madera, para sustentar una creciente participación de este material en la construcción. Por lo anterior, deben combinarse soluciones forestales tipo sumidero con soluciones mixtas que consideren producción sostenible.

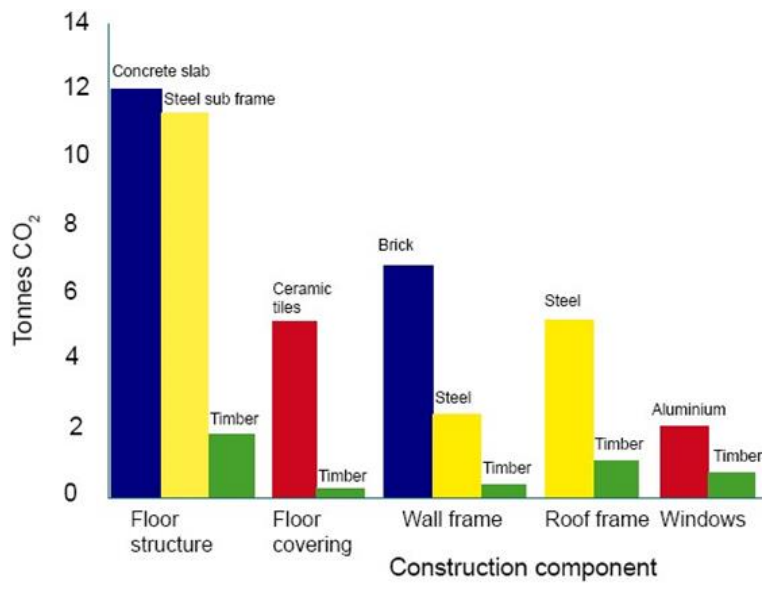

(Fuente: CRC For Greenhouse Accounting ${ }^{13}$ )

Figura $\mathrm{N}^{\circ} 5$

EMISIONES DE GASES DE EFECTO INVERNADERO PROCEDENTES DE LOS FABRICANTES DE LOS DIFERENTES COMPONENTES DE LA CONSTRUCCIÓN EN UNA CASA DE FAMILIA

\footnotetext{
11 https://blogs.funiber.org/medio-ambiente/2014/08/21/construir-con-madera-reduciria-las-emisiones-de-co2

12 (http://www.ecohabitar.org/madera-en-construccion-material-unico/).

13 http://www.aeim.org/index.php/madera-natura-renovable/)
} 


\section{COMENTARIOS FINALES Y CONCLUSIONES}

El sector forestal puede constituir un aporte importante al logro de la meta de carbono neutralidad del país para el año 2050 por la vía de la captura de carbono y la reducción de emisiones.

El enfoque de políticas públicas sectoriales no debe abandonar el concepto del desarrollo sustentable, lo que significa tomar en cuenta tanto las implicancias ambientales como las sociales y económicas de las posibles estrategias. En particular, es importante considerar las relaciones costo-beneficio de estas para lograr las metas deseadas sin someter a la sociedad a sacrificios excesivos e innecesarios.

No es correcto comparar plantaciones exóticas con bosque nativo en su capacidad de captura de carbono, asumiendo que las primeras serán cortadas para producción maderera y los segundos no. Lo que se está haciendo en este caso es comparar entre dos regímenes distintos; producción maderera versus régimen de sumidero permanente. Las comparaciones deben realizarse para ambos casos en régimen similar; exóticas versus nativas en régimen de producción y similar comparación para ambas como sumidero permanente.

Bajo los supuestos de análisis en este estudio y comparando regímenes similares, el carbono capturado por forestaciones de rápido crecimiento tiene un costo significativamente menor que las forestaciones con especies nativas, tanto en régimen de producción como en régimen de sumidero permanente.

Tampoco es correcto que solo se realice una comparación del carbono capturado, debe incluirse en la ecuación el carbono que se deja de emitir cuando se reemplazan materiales, como plásticos, acero, cemento y otros, por madera y sus derivados

Si bien en los regímenes de producción (especies exóticas y nativas con silvicultura intensiva) se puede capturar $\mathrm{CO}_{2}$ a costos inferiores que en los de sumidero permanente, en estos últimos se logra una mayor acumulación por unidad de superficie.

Reconociendo que existen preferencias en sectores de la sociedad por algunos tipos de especies en relación a otras, concretamente nativas respecto a exóticas, no existen elementos basados en la ciencia que permitan descartar el uso de especies introducidas si se toman las precauciones de realizar una silvicultura adecuada. Los elementos que más se debaten, son el uso del agua y la mayor concentración y continuidad de biomasa por parte de las plantaciones forestales, por su riesgo de incendios. En el primer caso, el uso de agua tiene directa relación con la producción de biomasa y, consecuentemente, con la captura de $\mathrm{CO}_{2}$, por lo que no solo debe analizarse la utilización de este recurso por hectárea, sino por tonelada producida de biomasa y tonelada capturada de $\mathrm{CO}_{2}$, lo que conduciría a conclusiones distintas. También debe considerarse la realidad de la pluviosidad de cada territorio para determinar la aptitud de acoger plantaciones de rápido crecimiento, pues en muchas situaciones esta realidad las permite sin dificultad. En el segundo caso, y como se ha podido apreciar en los grandes incendios de agosto y septiembre de 2019 en Brasil, Paraguay y Bolivia, las especies nativas no garantizan en ninguna circunstancia evitar siniestros catastróficos y en cualquier estrategia deben cumplirse prácticas adecuadas de silvicultura preventiva.

Las distintas especies y tipos de bosque permiten generar opciones de forestación para una diversidad de situaciones, territorios y condiciones de suelo y clima. Las especies nativas, muy valoradas por la sociedad por su potencial de constituir bosques diversos y su aporte de servicios ecosistémicos, requieren inversiones relativamente más altas, capturan carbono a mayor costo y no pueden ser establecidas en cualquier territorio o condición de suelo y clima. En base al análisis realizado, las opciones de regeneración 
asistida y de forestación con silvicultura intensiva y régimen de producción resultan ser las más costo-eficientes para estas especies. Las especies de rápido crecimiento, en tanto, pueden constituir soluciones funcionales para terrenos degradados y en procesos de erosión, así como para determinados climas, y si bien son menos valoradas por la sociedad en sus aspectos ambientales logran capturar carbono a menor costo, pueden establecerse en terrenos degradados, requieren menores inversiones y permiten encadenar actividades productivas en los territorios. El análisis realizado muestra que estas especies pueden efectuar también un aporte interesante bajo régimen de sumidero permanente, capturando y almacenando altos niveles de carbono a costos relativamente bajos para la sociedad.

Aunque en este trabajo solo se valorizaron las opciones que incrementan la superficie boscosa, a través de forestación o regeneración asistida, existe un amplio consenso en el ámbito de la ingeniería forestal sobre la conveniencia del manejo de los bosques nativos existentes que sean aptos para ello, para revertir situaciones de degradación y/o incrementar el potencial productivo y el valor para sus propietarios. Este último aspecto favorece tanto la conservación como la generación de empleos y cadenas productivas a escala local.

Debido al gran impacto de sustitución de materiales constructivos emisores y secuestro de carbono de la construcción en madera, las políticas forestales debieran no solo preocuparse de la captura de carbono, sino también de la producción ecoeficiente de madera, para sustentar una creciente participación de este material en la construcción. Por lo anterior, deben combinarse soluciones forestales tipo sumidero con soluciones mixtas que consideren producción sostenible.

La gran mayoría de los terrenos disponibles para forestación presentan significativos niveles de erosión, lo que dificulta y encarece el establecimiento de bosques de especies nativas. Limitar la estrategia de forestación solo a dichas especies reduciría sustancialmente el universo de superficie forestable. Para algunos de estos casos, puede ser útil considerar una primera fase con especies colonizadoras que permitan avanzar hacia una recuperación de superficies de especies nativas.

La gran mayoría de los terrenos disponibles son de propiedad privada, por lo que es importante considerar soluciones combinadas que movilicen la colaboración de los propietarios. En este sentido, el Estado deberá compensar las opciones que no presenten rentabilidad privada suficiente y algunas de ellas financiarlas en su totalidad, como en los casos de régimen de sumidero permanente. La magnitud de las inversiones requeridas hace conveniente generar, tanto como sea posible, estrategias que atraigan recursos privados, pues los recursos fiscales, siempre escasos, compiten con otras necesidades urgentes de la sociedad, como las pensiones, la educación, la salud y otras. Es también una responsabilidad con la sociedad asegurarse de lograr las combinaciones más costoeficientes en términos de pesos por tonelada de $\mathrm{CO}_{2}$ capturada o por empleo generado.

\section{REFERENCIAS}

Álvarez, S. y Grosse, H., 1978. Antecedentes Generales y Análisis para el Manejo de Lenga (Nothofagus pumilio. Poepp. et Endl Krasser) en Alto Mañihuales, Aysén. Tesis de grado, Facultad de Ciencias Forestales, Universidad de Chile.144 p.

Armesto. J. J.; Smith Ramírez, C.; Carmona, M. R.; Celiz Diez, J. L.; Díaz, I. A.; Gaxiola, A.; Gutiérrez, A. G.; Núñez Ávila, M. C.; Pérez, C. A. and Rossi, R., 2009. Old-Growth Temperate Rainforests of South America. Conservation, plant-animal interactions and baseline biogeochemical processes. In: Old-Growth Forests. Edited by C. Wirth, G. Gleisner, and M. Heimann, 207: 367-90. Berlin, Heidelberg: Springer, Berlin Heilderberg. 2009. https/doi.org/10.1007/978-3-540-92706-8_16. 
Asafu-Adjaye, John; Blomqvist, L.; Brand, S.; Brook, B.; DeFries, R.; Ellis, E.; Foreman, C.; Keith, D.; Lewis, M.; Lynas, M.; Nordhaus, T.; Pielke, R.; Pritzker, R.; Joyashree, R.; Sagoff, M.; Shellenberger, M.; Stone, R. and Teague, P., 2015. An Ecomodernist Manifesto Abril 2015; www.ecomodernism.org/manifesto

Bava, J., 1999. Los bosques de lenga en Argentina. En Silvicultura de los bosques nativos de Chile. Editores C. Donoso y A. Lara. Editorial Universitaria. Santiago de Chile. 273-296.

Beltrán, K., 2013. Superficie potencial forestable de las Regiones de O’Higgins a Aysén. Corporación Nacional Forestal. CONAF. 276.

Bren, L. and Hopmans, P., 2007. Paired catchment observations on the water yield of mature eucalypt and inmature radiate pine plantations in Victoria, Australia. Journal of Hydrology (2007).

Cabrera, J., 2007. El pago por servicios ambientales, conceptos y mercados. CIFOR. Volumen 13 №1. 177-186

Cabrera, J.; Villalobos, E. y Pugin, A., 2007. Boletín PSA. Boletín informativo № 2. Instituto Forestal. 8p.

Centro EARTH Universidad Adolfo Ibáñez, 2017. Actualización de estudio evaluación del aporte económico y social del sector forestal en Chile y análisis de encadenamientos, año 2017.

Cerda, I.; Olavarría, J. y Abalos, M., 1992. El Sector Forestal en Chile, Logros y Desafíos. Instituto Forestal Corporación de Fomento de la Producción, Santiago, Chile. pp 166.

CONAF, CONAMA, BRF, 2017. Catastro y Evaluación de los Recursos Vegetacionales Nativos en Chile. UACH/PUC/UCT. Informe Final.

CONAF, 2019. Ocurrencia y Daño de Incendios Forestales Nacional. Consolidado Temporadas 1985 -2019. Gerencia. Corporación Nacional Forestal.

Chambers, Jeffrey, Q.; Negron-Juarez, Robinson I.; Magnabosco Marra, Daniel; Di Vittorio, Alan; Tews, Joerg; Roberts, Dar; Ribeiro, Gabriel H. P. M.; Trumbore, Susan E. and Higuchi, Niro, 2013. The steadystate mosaic of disturbance and succession across an old-growth Central Amazon forest landscape. PNAS March 5, 2013110 (10) 3949-3954; https://doi.org/10.1073/pnas.1202894110. Edited by Peter M. Vitousek, Stanford University, Stanford, CA.

Donoso, C.; Morales, J., y Romero, M., 1990. Hibridación natural entre roble (Nothofagus obliqua (Mirb) Oerst. y raulí (Nothofagus alpina (Poepp. \& Endl.) Oerst, en bosques del sur de Chile. Revista Chilena de Historia Natural, 63: 49-60.

Elizalde, Rafael, 1958. La sobrevivencia de Chile. Ministerio de Agricultura. Dirección General de Producción Agraria y Pesquera. Santiago, Chile.

FAO, 2019. Global Demand for Wood Products. In: State of the World's Forests 2019. Disponible en: http://www.fao.org/3/i0350e/i0350e02a.pdf

Fenning, Trevor, M. and Gershenzon, Jonathan, 2002. Where will the wood come from? Plantation forests and the role of biotechnology. Trends in Biotechnology, FAO, 2002

Frascaria-Lacoste, N.; Gerard, Henry, A.; Bertolino, P.; Collin, P. and Manjarres E., 2011. Should Forest Restoration with Natural Hybrids Be Allowed? Restoration Ecology, 19(6): 701-704.

Frelich, Lee, 2016. Forest Dynamics. Published online 2016 Feb 17. doi: 10.12688/f1000research.7412.1

Gay, Claudio, 1838. Sobre las Causas de la Disminución de los Montes de la provincia de Coquimbo. Diario El Araucano, número 399, de abril de 1838, en: Libro Rojo de la Flora Nativa y de los Sitios Prioritarios para su Conservación: Región de Coquimbo" (F.A. Squeo, G. Arancio y J.R. Gutierrez, Eds.). Ediciones Universidad de La Serena, La Serena, Chile (2001) 19: 281-286.

González de Nájera, Alonso, 1889. Desengaño y reparo de la Guerra del Reino de Chile, de la colección Historiadores de Chile. Tomo XVI. José T. Medina. Imprenta Ercilla, Santiago, 1889.

Grosse, H., 2009. Silvicultura de brinzales y latizales en: Silvicultura del Bosque Nativo. Función Histórica y Opciones Futuras sobre la Base del Manejo Sustentable. ISBN: 978.956-318-019-0. Instituto Forestal, Chile. $135 p p$. 
Grosse, H. y Pincheira, M., 1998. Efecto del tamaño de contenedor en el desarrollo inicial de plantaciones de raulí (Nothofagus alpina Poepp. et Endl). Primer Congreso Latinoamericano IUFRO. Valdivia, Chile.

Grosse, H.; Quiroz, I.; Kannegiesser, U. y Valdés, M., 1991. Desarrollo de plantaciones de raulí y roble en función de su preparación en vivero y en terreno - sector Tremohue Jauja. En: Investigación manejo silvícola del bosque nativo. Informe final N0 5. INFOR-CORFO. 84-102.

Grosse, H.; Quiroz, I. y Valdés, M., 1993. Ensayos de época de plantación y tipo de planta. En: Investigación manejo silvícola del bosque nativo. Informe. INFOR-CORFO. 17-34.

Hartwig, Fernando, 1986. 75 Jahre Forstwirtschaft in Chile". Forstarchiv. Heft 6 Nov./Dez. 57. Jahrgang. 236243.

INFOR, 2018. Evaluación interna de la línea de Inventario Forestal Continuo de INFOR.

INFOR, 2019. Anuario Forestal 2019. Chilean Statistical Yearbook of Forestry. Instituto Forestal, Chile. Boletín Estadístico Nº 168 P. 214

Keith, H.; Mackey, B. G. and Lindenmayer, D. B., 2009. Re-evaluation of forests biomass carbon stocks and lessons from the world's most carbon-dense forests. Proceedings of the National Academy of Sciences 106(28), 11635-11640.

Martin, Carl,1923. Landeskunde von Chile. Hamburg, L. Friedrichsen \& Co. 786p.

Martin, Marjorie; Pilquinao, Bernardo; Müller-Using, Sabine; Bahamóndez, Carlos; Guiñez, Rodrigo; Acuña, Bernardo; Bava, José y Loguercio, Gabriel, 2014: Diagramas de Manejo de Densidad para Bosques de Lenga de Aysén y Magallanes con Fines de Producción de Madera. Instituto Forestal, Chile.

Molina, Juan Ignacio, 1810. Ensayo sobre la historia natural de Chile; Bolonia. Santiago Eds.

Mujica, R., 1997. Análisis económico privado de un plantación de Nothofagus alpina (Poepp et Endel) Oerst, ubicada en la provincia de Valdivia. Tesis, Facultad de Ciencias Forestales de la Universidad Austral de Chile. Valdivia. P. 132.

Nazif, Iván y Cabañas, Carlos, 2014. Plantaciones y Pobreza, CONAF 2014

Olivares de, Miguel, 1864. Historia militar, civil y sagrada de Chile. Colección de historiadores de Chile y de documentos relativos a la historia nacional. Santiago: Impr. del Ferrocarril, 1861-v.22. Biblioteca Nacional.

Otero, Luis, 2006. La huella del fuego. Pehuén Editores. María Luisa Santander 537, Providencia, Santiago.171p.

Otero, L.; Contreras, A. y Barrales, L., 1994. Efectos ambientales del reemplazo de bosque nativo por plantaciones. Ciencia e Investigación Forestal, Volumen 8, º2, 1994.

Ovalle, Alonso, 1646. Historica relación del Reyno de Chile y de las misiones y ministerios que exercita en el la Compañía de Jesus. Roma: Por Francisco Cavallo, 1646. Colección: Biblioteca Nacional.

Peña, Eduardo, 2014. Consideraciones para la creación de una franja de prevención de incendios en la interfaz urbana rural. Revista Mundo Forestal, Diciembre 2014.

Pérez Rosales, Vicente, 1886. Recuerdos del pasado (1814-1860). Santiago de Chile. Imprenta Gutenberg.

Pizarro, R; Sanguesa, C.; Arumi, J. L.; Iroumé, A.; García, P.; Vallejos, C.; Mendoza, R.; Pino, J.; Berrios, A.; Ibáñez, A.; Castillo, B. y Bernal, A., 2019. Antecedentes de la relación masa forestal y disponibilidad hídrica en Chile. UNESCO, PHI - VIII/ Documento Técnico N41, América Latina y El Caribe, 2019

Prado, José Antonio, 2015. Plantaciones Forestales, más allá de los árboles. Colegio de Ingenieros Forestales, 2015. 83 - 89

Prado, J. A.; Barros, S.; Wrann, J.; Rojas, P.; Barros, D. y Aguirre, S., 1986. Especies Forestales Exóticas de Interés Económico para Chile. Instituto Forestal - Corporación de Fomento de la Producción. Santiago, Chile. 168 p. 
Prado, J. A. y Barros, S. (Eds), 1989. Eucalyptus. Principios de Silvicultura y Manejo. Instituto Forestal Corporación de Fomento de la Producción. Santiago, Chile. 197 p.

Ríos, A., 2008. Desarrollo inicial de plantaciones de Raulí y Raulí-Roble de cinco años bajo un régimen de establecimiento intensivo en la depresión intermedia de la Región de los Ríos, Chile”. Tesis de grado. UACH.

Rosales de, Diego, 1674. Historia general del Reyno de Chile: Flandes Indiano" Valparaíso: Impr. del Mercurio, Colección: Biblioteca Nacional. Publicada por Benjamín Vicuña Mackenna entre 1877 y 1878.

Schmidt. H. y Urzúa, A., 1982. Transformación y manejo de los bosques de lenga en Magallanes. Editorial: Facultad de Ciencia Agrarias, Veterinarias y Forestales Universidad de Chile, Santiago de Chile.

Sohngen, Brent; Mendelsohn, Robert and Sedjo, Roger A., 2001. A Global Model of Climate Change Impacts on Timber Markets. Journal ofAgricultural and Resource Economics 26(2):326-343

Copyright 2001 Western Agricultural Economics Association.

Stolpe, N. B.; Dube, F. and Zagal, E., 2010. Calibration of $\mathrm{CO}_{2} \mathrm{FIX}$ to native forests, pine plantation and pasture on a volcanic soil of the Chilean Patagonia. Acta Agriculture

Sutton, W. R. J., 1995. Plantation forests protect our biodiversity. N. Z. For. 40(3): 2-5.

Toro, Jorge, 2008. Efecto del cultivo de Pinus radiata, sobre un suelo erosionado. Forestal Mininco, Gestión Ambiental. Concepción, Mayo 2008.

Trivelli, Hugo, 1970. Discurso de la tierra, en La Sobrevivencia de Chile. Ministerio de Agricultura, SAG. Santiago de Chile. Páginas XV-XXVII.

Tuley, G., 1980. Nothofagus in Britain. Forestry Commission. Forest Record. 122. P. 26.

UNTEC - Universidad de Chile, 2014. Evaluación del Aporte Económico y Social del Sector Forestal en Chile

UPM - Kimmene, 2011. From forest to paper, the story of our water footprint. A case study for the UPM Nordland Papier Mill”. August 2011. Disponible en: https://waterfootprint.org/media/downloads/UPM-2011.pdf

Urrutia- Jalabert, R. Malhi, Y. and Lara, A., 2015. The oldest, slowest rainforests in the world? Massive biomass and slow carbon dynamics of Fitzroya cupressoides temperate forests in southern Chile. PloS one, 10(9), e0137569.

Veblen, T. T. and Ashton, D. H., 1978. Catastrophic influences on the vegetation on the Valdivian Andes, Chile. Vegetatio 36: 149-167.

Veblen, T. T.; Ashton, D. H. and Schlegel, F. M., 1979. Tree regeneration strategies in a low-land Nothofagusdominated forest in south-central Chile. J. Biogeog. 6: 329-340.

Veblen, T. T.; Ashton, D. H.; Schlegel, F. M. and Escobar, R. B., 1980. Structure and dynamics of old growth Nothofagus forests in the Valdivian Andes, Chile, J. Ecol. 68. 1-31.

Veblen, T. T.; Donoso, Z. C.; Schlegel, F. M. and Escobar, R. B., 1981. Forest Dynamics in south-central Chile. J. Biogeg. 8: 211-247.

Villalobos, E., 2007. Servicios ambientales. En: Silvicultura del Bosque Nativo. Función Histórica y Opciones Futuras sobre la Base del Manejo Sustentable. ISBN: 978.956-318-019-0. Instituto Forestal, Chile. 135pp.

WWF, 2012. Living Forests Report, Chapter 4: Forests and Wood Products. 
